[Aus dem hygienischen Institut der Königl. Universität zu Breslau.]

\title{
Beiträge zur Frage der \\ Durchgängigkeit von Darm und Nieren für Bakterien.
}

$$
\text { Von }
$$

Dr. E. Opitz,

z. Z. Assistenzarzt der Königl. Universitâts-Frauenklinịk in Berlín.

\section{Durchgängigkeit des Darmes.}

In den letzten Jahren ist vielfach der Versuch gemacht worden, die bei einigen Bakterien, z. B. dem Bacillus der Fleischvergiftung Kaensche $\left(48^{\mathrm{a}}\right)$ beobachtete Fähigkeit, die Darmwand zu durchdringen und eine septische Infection des Körpers herbeizuführen, zu verallgemeinern. Es lag ja auch nahe, für die von versehiedenen Seiten berichteten Bakterienbefunde im Blute die Quelle im Darme zu suchen, der normaler Weise so zahlreiche, zum Theil pathogene Bakterien beherbergt, Bestrebungen, die zur Aufstellung des Krankheitsbildes der „Darmsepsis" führten. Inzwischen ist durch zahlreiche Untersuchungen einwandsfrei festgestellt worden, dass der grösste Theil jener Bakterienbefunde im Blute auf Fehlern in der Technik beruhte. Die Frage aber, ob der normale Darm für Bakterien durchgängig ist oder nicht, ist vielfach in bejahendem Sinne beantwortet worden, einige französische Autoren besonders gehen sogar so weit, einen regelmässigen Durchtritt von Bakterien in den Säftestrom zusammen mit der aus dem Darme aufgenommenen Nahrung feststellen zu wollen.

In einer aus dem Flügge'schen Institute hervorgegangenen Arbeit tritt M. Neisser (72) diesen Bestrebungen entgegen auf Grund einer Reihe von Versuchen. Diese Arbeit ist Gegenstand einer abfälligen Kritik 
von Seiten Béco's (8) geworden. Der belgische Forscher stützt sich dabei auf eine eigene, von Neisser übersehene, experimentelle Arbeit (7). Der Zweck der folgenden Zeilen ist es, die Einwände Béco's auf ihre Berechtigung zu prüfen und mit Hülfe neuer Versuche die beregte wichtige Frage einer definitiven Lösung näher zu führen. Zunächst muss ich auf den ersten Aufsatz von Béco etwas näher eingehen.

Béco stellt sich zwei Fragen:

1. Geschieht das Eindringen der Mikroben aus dem Darme während des Lebens oder nach dem Tode?

2. Ist dieses Eindringen an Erkrankungen oder functionelle Störungen des Darmcanals gebunden?

Zur Beantwortung werden Leichenuntersuchungen und das Experiment herangezogen.

Von 27 menschlichen Leichen wurde $1 / 4$ bis $3 / 4$ Stunden nach dem Tode die Milzpulpa untersucht, später bei der Autopsie (nach 24 Stunden) yon einer anderen Stelle der Milz nochmals Material entnommen, ausserdem $11 \mathrm{Mal}$ von der Thyreoidea und $12 \mathrm{Mal}$ vom Herzblut Culturen angelegt. Es fanden sich in 11 Fällen unmittelbar nach dem Tode nur das Bacterium coli, in 4 Fällen daneben Staphylokokken, welche aber bei der Autopsie verschwunden waren. 1 Mal wurde das Bacterium coli nur im Herzblut und 2 Mal nur in der Thyreoidea gefunden. 4 Mal trat es erst bei der Section in der Milz auf. In 7 Fällen wurden nirgends Bakterien gefunden. Für die 4 Fälle, in denen das Bacterium coli erst bei der Section sich zeigte, wird die Annahme einer postmortalen Einwanderung zurückgewiesen. Die Blutinfection erfolge bei vielen Kranken in den letzten Lebensstunden, unabhängig von Darminfectionen.

Nach dem Vorgange von Bonchard (14) und Wurtz (110) trat er der Frage experimentell näher.

Das Resultat der Versuche war Folgendes:

1. 3 Kaninchen plötzlich getödtet, sämmtliche Organe steril.

2. 3 Kaninchen mit Arsenik vergiftet, Tod nach 15 bis 30 Stunden. Bei allen Thieren zahlreiche positive Röhrchen; gefunden wurde Subtilis, ein Streptococcus, Bacterium coli und Proteus vulgaris.

3. 1 Hund, 4 Kaninchen per os mit Cantharidin vergiftet, Tod nach $1 / 2$ bis 6 Tagen. Bei dem nach 12 Stunden gestorbenen Thiere Organe steril, bei den anderen fanden sich Bakterien.

4. Brechweinstein, subcutan in verschiedenen Dosen. Trat der Tod nach $2 \frac{1}{3}$ bis 7 Tagen ein, so waren Bakterien ins Blut übergegangen (7 Kaninchen).

1 Leider sind über die hier angewandte Technik, ebenso wie über die Dosen der zur Vergiftung der Thiere in den Experimenten verwandten Arzneimittel, genauere Angaben nicht gemacht. 
Bei grösseren Dosen, die den Tod vor 24 Stunden herbeiführen, bleiben die Organe steril ( 6 Kaninchen). Bei so schnell vergifteten Thieren fanden sich die Organe auch steril, wenn die Section erst 24 Stunden bis 9 Tage nach dem Tode gemacht wurde, während die Thiere bei $15^{\circ}$ gelegen hatten.

Aus diesen Resultaten zieht Béco den Schluss, dass langsame Vergiftung zum Eindringen von Darmbakterien in den Kreislauf während des Lebens führt, nicht so die schnelle Vergiftung. Nur sehr langsam wird der beim Tode nicht inficirte Leichnam von Bakterien besetzt.

Ich glaube, dass die Sterilität der Organe bei den schnell vergifteten Thieren auch nach langem Liegen sich einfach dadurch erklären lässt, dass die angewandten Mittel selbst in der nöthigen Concentration vorhanden waren, um, wenn auch nicht die vorhandenen Bakterien zu tödten, so doch ihre Entwickelung zu hemmen. Wissen wir doch, hauptsächlich aus den Arbeiten von Koch und Behring, dass dazu schon sehr geringe Concentrationen antiseptisch wirkender Körper genügen. ${ }^{1}$

Ferner ist zu bemerken, dass der Werth der Züchtung in flüssigen Medien beträchtlich geringer ist als derjenige in festen Substraten. Nur durch die letztere Methode allein ist es möglich, die Menge der ausgewachsenen Keime, ihre Natur und ihr Verhältniss unter einander, sowie eventuelle Verunreinigungen als solche festzustellen, nicht aber durch die Bouilloncultur. Noch mehr beeinträchtigt wird der Werth der Versuche durch die Mittheilung, dass in den als positiv gerechneten Fällen ,zahlreiche" Röhrchen Bakterienwachsthum zeigten. Das heisst doch wohl, dass ein Theil der Röhrchen steril blieb, was beim wirklichen Vorhandensein von Bakterien in einigermassen beträchtlichen Mengen ausgeschlossen wäre. Zufällige Verunreinigungen können in den negativen Fällen durch das mit den untersuchten Organen übertragene Antisepticum am Auskeimen verhindert worden sein und in den positiven Fällen die alleinige Ursache der beobachteten Trübung der Bouillonröhrchen gebildet haben.

Auf dieser angeführten Arbeit fussend, greift Béco in einem neuen Aufsatz M. Neisser an und sucht die Resultate desselben in Frage zu stellen. Zur Beweisführung werden die Versuche von Nocard (74) und Desoubry et Porcher (28) angeführt, nach denen während der Verdauung grosse Mengen von Bakterien mit dem Chylus fortgeführt würden und in den Kreislauf gelangten.

Angesichts der entgegengesetzten Resultate M. Neisser's fordert Béco indessen noch weitere Untersuchungen über die Grenze, bis zu der die Schutzkraft der Darmmucosa reicht.

$\mathrm{Ob}$ die Invasion des Körpers durch das Bacterium coli erst nach dem Tode oder in agone erfolgt, sucht Verf. durch seine oben citirten Wahr-

\footnotetext{
${ }^{1}$ Vergl. auch Gottschlich in Flügge's Mikroorganismen. I. S. $433 \mathrm{ff}$.
} 
nehmungen festzustellen. Aus dem Resultate dieser und der Beobachtung, dass bei Versuchsthieren, die, zu anderweitigen Zwecken benutzt, an Durchfällen eingingen, sich unmittelbar nach dem Tode in allen Organen das Bacterium coli fand, und analogen Beobachtungen von Teissier zieht Béco den Schluss, dass gegen das Lebensende häufig die Darmwand für die Darmbakterien durchgängig wird. Ja, es sei sogar möglich, mit grosser Sicherheit experimentell das Durchwandern der Darmbakterien durch die Darmwand zu bewirken. Das Eindringen sei aber ein accessorischer Vorgang ohne Bedeutung für das Fortbestehen des Lebens. Denn Wurtz und Hudélo (112) fanden bei Thieren nach Verabreichung nicht tödtlicher Dosen Alkohol in den Organen keine Bakterien, ebenso der Verf. bei seinen Versuchsthieren, die erst 2 bis 4 Wochen nach Vergiftung mit Fowler'scher Lösung starben.

Beim Vergleich mit den Tabellen in der Neisser'schen Arbeit wendet sich Verf. gegen die Auffassung, dass ein Theil der erhaltenen, nicht sterilen Sectionen auf Versuchsfehler zu beziehen sei und nimmt das Resultat, im Gegensatz zu Neisser, als Beweis für seine Auffassung an.

Der Eintritt der Leichenfäulniss scheint dem Verf. davon abzuhängen, $o b$ in Agone ein Durchtritt von Bakterien durch die Darmwand statt hatte oder nicht. Es sei möglich, dass bei geringer Herabsetzung der Widerstandsfähigkeit die Bakterien den Darm durchdringen könnten, aber im Blute zerstört oder durch die Niere ausgeschieden würden. Unter anderen Umständen könnten sich diese Bakterien in den wenig widerstandsfähigen Organen festsetzen und eine "latente multiplication" finden (S. 517). Als Beispiel wird ein Fall angeführt, in dem bei vollstem Wohlsein 6 Jahre nach überstandenem Gelenkrheumatismus plötzlich eine Peritonitis ausbrach, die von einer durch den Staphylococcus pyogenes albus zur Vereiterung gebrachten Mesenterialdrüse ausging. Hier soll die Infection vom Darme ausgegangen sein (und 6 Jahre latent bestanden haben?). Béco glaubt gezeigt zu haben, dass Neisser sich im Widerspruche befinde mit den festgelegten wissenschaftlichen Erfahrungen. -

Auf einige Punkte der Arbeit Béco's sei gleich an dieser Stelle eingegangen! Dem zuletzt angeführten Falle kann ich nicht die geringste Beweiskraft für Béco's Anschauungen zuerkennèn, da ein Zusammenhang zwischen der vor 6 Jahren stattgehabten Darmerkrankung und der Vereiterung der Mesenterialdrüse auch nicht im entferntesten wahrscheinlich gemacht ist.

Der gegen M. Neisser erhobene Vorwurf, dass er sich im Widerspruche mit seinen sonst vertretenen Anschauungen als Anhänger der „Coli-Bacillosis" bekenne, beruht lediglich auf einem Missverständnisse. Neisser's Angabe, dass die Möglichkeit des Durchdringens der Darmwand für einzelne der ,zur grossen Gruppe der Colibakterien gehörigen Arten" erwiesen sei, bezieht sich auf die Bakterien der Fleischvergiftung ${ }^{1}$

\footnotetext{
I Vgl. Kaensehe (48a).
} 
DURChä̈Ngrgkeit von DarM UNd Nieren für Bakterien. 509

und ist lediglich im botanischen Sinne zu verstehen. Damit erledigt sich also die Sache von selbst.

Bezüglich der Litteratur über den Gegenstand kann ich auf die M. Neisser'sche Arbeit verweisen, nur einige Arbeiten muss ich zur Ergänzung und Fortführung der dort gemachten Angaben besprechen.

Wurtz und Herman (109) fanden bei 32 Leichen, von denen 26 an Tuberculose zu Grunde gegangen waren, 24 bis 36 Stunden nach dem Tode $15 \mathrm{Mal}$ in der Leber, $12 \mathrm{Mal}$ in den Nieren und $6 \mathrm{Mal}$ in der Milz das Bacterium Escherich, und zwar war dasselbe, wenn in der Milz, so auch in den anderen Organen vorhanden. Die Frage, ob es sich dabei um eine Leichenerscheinung oder eine Einwanderung während des Lebens handelt, ist nicht $z u$ beantworten.

Létienne (62) fand in 24 von 42 untersuchten Gallenblasen von mensehlichen Leichen Bakterien (16 Arten). Wie lange nach dem Tode die Untersuchung vorgenommen wurde, ist nicht angegeben, so dass den Angaben nicht viel Werth beizumessen ist. 4 von 5 getödteten Meerschweinchen hatten in Galle und Urin Bakterien, eine Angabe, die den bisher bekannten Thatsachen widerspricht. Verf. sucht sie durch die Annahme einer latenten Erkrankung der Thiere zu erklären.

Korkunoff (57) spricht sich auf Grund von Versuchen mit Bac. Neapolitanus und Milzbrand dafür aus, dass eine Infection vom Darmcanal bei normaler Schleimhaut nicht möglich ist.

Lesage et Mecaigne (61) fanden in Uebereinstimmung mit Welch (113) nur bei Darmveränderungen das Bact. coli in den Organen. Die Galle scheint zuerst inficirt zu werden, und zwar schon während der Agone. In die Lungen scheinen bei Lungenkrankheiten auch Bakterien einzuwandern.

Ackard und Phulpin (1) untersuchten 49 Fälle während der letzten Lebensstunden und nach dem Tode auf die Anwesenheit von Bakterien im Venenblute und der Leber. Bei 10 Patienten fanden sie in agone Bakterien im Blut oder in den Organen.

In den positiven Fällen hatte die Untersuchung stattgefunden 10 Minuten bis 8 Stunden vor dem Tode. In 24 Fällen wurden erst nach dem Tode Mikroorganismen gefunden, meist zuerst in der Leber. Die Verfasser meinen eine Abhängigkeit der Schnelligkeit der Einwanderung nach dem Tode in die Organe von der Temperatur und von der Art der Erkrankung feststellen zu können. Die Leber wird am leichtesten und dementsprechend meist zuerst inficirt, das Blut kann von hier aus, direct rom Darm oder auch unter besonderen Umständen von der Lunge aus inficirt werden.

Nach Wurtz und Hudélo (112) kann eine Vergiftung mit nicht tödtlichen Dosen Alkohol den Durchtritt von Bakterien ins Peritoneum und das Blut hervorrufen.

Gilbert et Fournier (39) folgern aus dem Befunde, dass von 30 untersuchten Gallensteinen ( 27 vom Menschen und 3 vom Rinde) 11 lebende Bakterien enthielten, dass bei Lebzeiten ein Eindringen von Bakterien in die Gallenblase stattfinde und so zu Concretionen Veranlassung geben könnte. 
Sehr werthvolle Beiträge zur vorliegenden Frage enthält die Dissertation ron Birch-Hirschfeld (9), die eine sehr reichhaltige Litteraturübersicht bringt. Die Annahme Bẻco's, dass ein postmortales Eindringen des Bacterium coli nicht die Regel bilde, ebenso, dass den Weg der Einwanderung die Blutbahn bilden müsse, wird von Birch-Hirschfeld zurückgewiesen; dagegen bestätigt er nach eigenen Versuchen den Schluss Béco's, dass zwischen Darmaffectionen und Einwanderung kein Zusammenhang bestehe. Für die Möglichkeit der Durchwanderung des Bacterium coli durch die Darmwand nach dem Tode sprechen Schnittpräparate vom gesunden Darm, die in allen Schichten, auch in der Serosa, Stäbchenbakterien nachweisen liessen, und das Ergebniss eines Versuches, in dem aus einer sofort nach dem Tode herausgenommenen Darmschlinge durch die Wand das Bacterium coli und eine verflüssigende Stäbchenart in die umgebende Bouillon auswanderten. Eine steril herausgenommene und 24 Stunden in einer Colibouilloncultur belassene Mäuseniere zeigte zahlreiche Stäbchen in den davon angefertigten Schnittpräparaten, hauptsächlich in den Gefässen, aber auch durch das gesammte Gewebe zerstreut. Ferner weist Birch-Hirschfeld auf die Möglichkeit eines agonalen Einwanderns von Bakterien von der Lunge aus hin. Den Schluss der Arbeit bildet die Besprechung der Untersuchung von 20 Leichen in verschiedener Zeit nach dem Tode in Bezug auf den Augenblick des Erstauftretens des Bacterium coli in den Organen. Es konnte kein bestimmter Typus der Reihenfolge, in der die Organe befallen werden, und für den Grad der Beeinflussung durch die Temperatur festgestellt werden.

„Von besonderem Interesse ist der Umstand, dass auch bei plötzlichen Todesfällen, die, wie die Section ergab, ganz gesunde Individuen betrafen (1 Apoplexie, 2 Selbstmorde, 2 Verbrennungen), Bacterium coli in relativ kurzer Zeit nach dem Tode in den Organen der Leiche nachzuweisen war." Die kürzeste Zeit nach dem Tode, zu welcher Bakterien im Blute oder den Organen nachgewiesen werden, ist eine Stunde. Nur in einem einzigen Falle (XV, Apoplexie) fanden sich bei der ersten Untersuchung $1 \frac{1}{2}$ Stunden post mortem in keinem der Organe Bakterien. Die erste Entnahme geschah in 16 Fällen zwischen 1 bis 5 Stunden, in 2 Fällen nach 9 Stunden und bei den beiden Selbstmördern 17 Stunden nach dem Tode.

Mit demselben Gegenstande beschäftigt sich Hauser (43) in einer sehr sorgfältigen Arbeit. Er untersuchte bei 80 Leichen Blut, Galle und Harn und fand nur $11 \mathrm{Mal}$ keine Bakterien. Unter diesen sind gewiss noch einige (vergl. Fall 10), bei denen sich in den Organen durch anaërobe Züchtung Bakterien hatten nachweisen lassen, die ohne dies der Feststellung entgingen. Staphylokokken fand Hauser nur $3 \mathrm{Mal}$, während sie sonst viel häufiger beobachtet wurden. Dieser Umstand spricht sehr gegen die Verlässlichkeit anderer Angaben, da Staphylokokken in der Luft und auf der Haut so ausserordentlich verbreitet sind und deshalb sehr häufig zu Verunreinigungen Veranlassung geben können. (Vergl. hierüber Kühnau [60].)

Die Lufttemperatur scheint nach Hauser einen bedeutenden Einfluss auf die Schnelligkeit des Eindringens der Bakterien auszuüben.

Zum Nachweis der Möglichkeit einer postmortalen Wanderung wurden in getödteten Thieren und in Menschenleichen in verschiedenen Körperhöhlen Pyocyaneusculturen eingegossen und nach Ablauf einiger Zeit entfernt und nahe liegende Organe auf das Vorhandensein dieser Bakterien untersucht. 


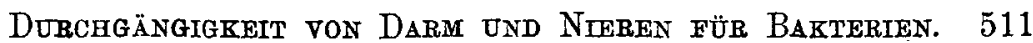

In einem grossen Procentsatz der Fälle, der sich nach Art der Lage der Cadaver und des gewählten Eingussortes änderte, fanden sich die Bakterien wieder. Beim Menschen war die Zahl der positiven Fälle erheblich geringer als bei Thieren, ein Umstand, der von Hauser meines Erachtens mit Recht auf den grossen Unterschied der Körpergrösse und der Temperatur - diese war für die Thierversuche höher - zurückgeführt wird. Die Art der Verbreitung zeigte durchaus nichts Typisches.

Den Schlüssen Hauser's, dass die Möglichkeit einer rein postmortalen Wanderung hierdurch erwiesen ist und dass Folgerungen aus den postmortalen bakteriologischen Befunden nur mit grosser Vorsicht zu ziehen sind, kann man nur beipflichten. Man muss ja noch berücksichtigen, dass der Pyocyaneus als fast obligater Aërobier und mit geringerer Beweglichkeit, als z. B. das Bacterium coli ausgestattet, unter sehr ungünstigen Verhältnissen sehr häufig sich weit in den Leichen verbreitet hat, trotzdem or sich seinen Weg im Kampfe gegen schon angesiedelte Mikrobien bahnen musste. Sehr viel günstiger liegen natürlich die Bedingungen für eine Ausbreitung des Bacterium coli, so dass man auf die Mōglichkeit einer sehr schnellen Wanderung dieses und anderer Mikrobien rechnen bann.

Chrostek und Egger (23) berichten über Experimente, die im Anschluss an Bouchard, Wurtz, Charrin und Béco an einer grossen Reihe von Thieren angestellt wurden. Es fanden sich unter 13 erfrorenen Kaninchen bei 4 im Blut des Herzens und der Vena cava Bakterien; die Controlthiere ergaben durchweg ein negatives Resultat. In 50 Serien von je 3 Mäusen, deren eine durch Genickstich, eine durch Erfrieren getödtet, und bei noch schlagendem Herzen auf den Keimgehalt des Herzblutes untersucht wurde, während die dritte erst zwei Stunden nach dem Tode zur Untersuchung kam, erhielten die Forscher bei den Controlthieren $3 \mathrm{Mal}$, bei den erfrorenen und bei noch schlagendem Herzen untersuchten Mäusen $22 \mathrm{Mal}$, aber bei den 2 Stunden nach dem Tode geprüften Thieren nur $8 \mathrm{Mal}$ Bakterien auf den Platten. Von 14 im Hungerzustande erfrorenen Mäusen ergab nur eine ein positives Resultat. Im Blute von 31 erstickten Mäusen wurden 6 Mal Bakterien gefunden. Die Befunde bei den schnell getödteten und im Hungerzustande untersuchten Thieren werden als Versuchsfehler gedeutet, während die Häufigkeit der positiven Ergebnisse (44 Procent bezw. 16 Procent) bei den anderen Thieren den Verfassern dafür zu sprechen scheinen, dass während der letzten Augenblicke des Lebens thatsächlich eine Einwanderung von Mikroorganismen in die Blutbahn stattgefunden hat, als deren wahrscheinlichster Ort der Darm angenommen wird. Eine weitere Reihe von Versuchen an 27 Paaren Mäuse, die durch Erfrieren bezw. plötzlich getödtet und 12 Stunden post mortem untersucht wurden, ergab als Resultat 14 positive Fälle bei den plötzlich getödteten und 8 bei den erfrorenen Thieren (52 Procent bezw. 30 Procent). Die Erklärung für diesen Unterschied sehen Chvostek und Egger in dem geringen Kothgehalt des Darmes bei den erfrorenen Thieren.

Das Peritoneum, das jedes Mal mit untersucht wurde, gab etwas höhere positive Zahlen als das Blut. Nur bei den erfrorenen Thieren, die bei 
schlagendem Herzen untersucht wurden, kamen weniger positive Befunde vor (44 Procent gegen 34 Procent). Leider ist nicht gesagt, ob immer bei den einzelnen Thieren die Befunde übereinstimmten und wie häufig Blut und Peritoneum verschiedene Befunde lieferten. Auffallend sind die hohen und nur wenig von einander verschiedenen Zahlen der positiven Befunde im Peritoneum bei den 12 Stunden post mortem secirten Thieren (70 Procent und 67 Procent), während der Unterschied im Blutbefunde weit grösser ist (52 Procent und 30 Procent). Die Verfasser glauben den Nachweis geliefert zu haben, dass unter Umständen agonal eine Invasion von Mikrobien in die Blutbahn erfolgen kann, und zwar mit Sicherheit vom Darme aus. Die Ursache für die Bakterieninvasion bilden günstigere Bedingungen für den Austritt der Bakterien aus dem Darm und verminderte vitale Energie der Gewebe.

Im Zusammenhange mit dieser Arbeit steht ein weiterer Aufsatz Chrostek's (22). Unter Berücksichtigung der Litteratur kommt er zu dem Schlusse, dass postmortale bakteriologische Befunde nur von sehr beschränktem Werthe sind, auch beim Nachweise pathogener Arten, sofern diese nur im Darme oder sonst vorkommen können (S. 27, 34), dass gegenüber der erwiesenen(?) Möglichkeit eines agonalen Eindringens von Bakterien selbst der geführte Nachweis eines postmortalen Eindringens von Mikroorganismen aus Darm, Lunge $u$. s. w. in den Hintergrund treten müsse (S. 15) und dass keinesfalls die frühere Ansicht zu Recht bestehen kann, wonach nur schwere anatomische Veränderungen der Darmwand den Durchtritt von Bakterien ermöglichen würden (S. 17).

Bezüglich des ersten Punktes kann ich mich ihm nur anschliessen. Aber die für die letztere Ansicht angezogenen Arbeiten von Bizzozzero (10) und Ribbert (85) betonen gerade, dass diese Verhältnisse nur im Coecum des Kaninchens, sonst nirgends und bei keinem anderen Thiere gefunden seien und die Bedeutung ihrer Befunde ist durch Manfredi (69), der aus der Darmwand keine Bakterien züchten konnte, zu Nichte gemacht worden. Dass nach Abbindung des Darmes, wie sie Lewin und Posner (83) vornahmen, ein Befund von Bacterium coli in Peritoneum und Blase nichts für normale Verhältnisse beweist, liegt doch bei dem colossalen Eingriff auf der Hand. Ebenso steht es mit Boennecken (11); dessen mikroskopischen Präparaten stehen die weiter unten erwähnten von $\mathrm{Bosc}$ und Blanc gegenüber.

Der Erklärung Chvostek's für die auffallende Thatsache, dass der Procentsatz der positiven Befunde im Blute erfrorener Mäuse bei Untersuchung in agone höher ist als 2 Stunden post mortem, kann ich nicht beipflichten. Die während des Lebens in die Circulation gelangten Keime sollen z. B. den baktericiden Kräften des Blutes nach dem Tode zum Opfer fallen und ein weiteres Einwandern aus dem Darme unterbleiben. Viel natürlicher scheint es mir, die Ursache des Unterschiedes in den Befunden mit Trombetta (102) und entsprechend den oben angeführten 
Durchgängtgkeit VON Darm UNd NimRen für Bakterien. 513

Befunden von Birch-Hirschfeld und Hauser in dem ungleichmässigen Einsetzen der Fäulniss in den verschiedenen Organen zu suchen, eine Erkiärung, die Chvostek und Egger ohne Begründung zurückweisen. ${ }^{1}$ Auch die Annahme, dass die Kothentleerung bei den erfrorenen Mäusen der zweiten Versuchsreihe die geringere Zahl positiver Befunde gegenüber den schnell getödteten Mäusen verursachen soll, ist nicht sehr wahrscheinlich. Es bleibt auch dann noch immer eine ungeheuere Zahl Bakterien im Darme, die bei der nach Chrostek für eine Einwanderung günstigèn Hyperämie des Darmes und der herabgesetzten Vitalität der Epithelien zu einer schnellen Ueberfluthung der Organe mit Bakterien führen müssten. Zusammengehalten mit den Peritonealbefunden und der geringen Zahl positiver Befunde im Blute bei den erfrorenen und 12 Stunden post mortem untersuchten Mäusen scheint mir nichts weiter daraus hervorzugehen, als dass hier Verhältnisse vorliegen, die ausserordentlich wechselnd sind und deren Bedingungen wir noch nicht auch nur annähernd beurtheilen können. Welche Rolle Vèrsuchsfehler dabei spielen, lässt sich auch nicht procentualiter bestimmen. So z. B. ist die Schwierigkeit, steril zu seciren, bei den noch lebenden Thieren gewiss erheblich grösser und die Nothwendigkeit, sich zu beeilen, um das. Herz noch in Thätigkeit vorzufinden, wirkt nicht fördernd auf die Asepsis. Das Einzige, was mir erwiesen zu sein scheint, ist, dass postmortal eine sehr schnelle Invasion erfolgen und dass dieselbe vielleicht schon agonal beginnen $\mathrm{kann}$. Wie weit dafür der Darm in Betracht kommt, ist nicht festgestellt.

Während des Lebens suchte Macklezew (65) in ähnlicher Weise wie Boennecken die Durchgängigkeit der Darmwand für Bakterien zu prüfen. Er fand, wenn er den Darm abklemmte und in einen Condom schob, oder ihn an zwei Stellen ligirte, den Anus vernähte oder die Darmvenen abklemmte, bei der nach einiger Zeit wiederholten Laparotomie und Aufsaugen der Flüssigkeit mit Watte häufig Bakterien, auch wenn nur Hyperämie eingetreten war.

Bei der Schwierigkeit, mit Sicherheit Verunreinigungen bei dem vielen Manipuliren auszuschliessen, ist wohl für die vertretene Ansicht nichts bewiesen.

Teissier (99) fand zuweilen nach intrastomachaler Darreichung des Tetragenus Uebergang ins Blut und Sepsis, dabei waren aber stets intensive Darmentzündung und zuweilen Abscesse vorhanden, die mir eine allgemeine Infection erklären, auch ohne die Annahme einer Durohgängigkeit der unverletzten Darmwand.

1 Ein classisches Beispiel für diese Ungleichmässigkeit ist der Sectionsbefund bei Kaninchen 6 in meinen Protocollen.

Zeitschr. f. Hygiene. $X X I X$. 
Bosc et Blanc (12 und 13) fanden bei mikroskopischer Untersuchung der Darmwand von eingeklemmten Brüchen Bakterien nur bei Epitheldesquamation und Nekrose mit Hämorrhagieen. Die Bakterien waren nur in der Mucosa und Submucosa nachzuweisen, nicht in der Muscularis, bis auf wenige Keime im Innern erweiterter Gefässe, ziemlich zahlreich aber unter dem Peritoneum. Nur bei sehr schweren Veränderungen waren sie überall reichlich. Bei leichten Läsionen findet keine Einwanderung statt. Das intacte Epithel bildet eine Schranke; ist es zerstört, so dringen die Bakterien ein, finden aber in der Muscularis grossen Widerstand. In den Bruchsack dringen sie unter solchen Umständen auch vor, das Bacterium coli zeigt dann vermehrte Virulenz.

Bei einzelnen Thierversuchen fanden die Autoren nichts, bei anderen Bacterium coli und Kokken.

Wie man sieht, sind sehr verschiedene Meinungen über die Frage der Bakterienwanderung durch den Darm vertreten. Zur weiteren Klärung der Sachlage habe ich deshalb auf Veranlassung des Hrn. Professor Flügge eine Reihe von Untersuchungen vorgenommen, die zum Theil eine directe Fortsetzung der Versuche M. Neisser's darstellen.

Es wurden 101 Mesenterialdrüsen von 45 Rindern und 29 Drüsen von 12 Kälbern auf ihren Keimgehalt untersucht.

Die Technik war folgende: Aus dem Mesenterium frisch geschlachteter Rinder wurden die Drüsen ausgeschält, sofort ins hygienische Institut gebracht und verarbeitet. Um den Einwand auszuschliessen, dass etwa ein verwandtes Desinficiens die Entwickelung von Keimen verhindere, liess ich die von Neisser angewandte Sublimatspülung fort. Nach Befestigung der Drüsen auf einem Brette vermittelst ausgeglühter Nadeln wurde das Fett abpräparirt, ein grosser Theil der Oberfläche mit dem Paquelin verschorft und aus diesem Theile mit ausgeglühtem und $a b-$ gekühltem Messer ein Stück Gewebe herausgeschnitten, das in Gelatine oder Agar gegeben wurde. Von der so entstandenen Oeffnung ans drang ich mit dem Messer oder später mit einem feinen scharfen Löffel tief in die Drüse unter den nicht verschorften Theil ein, wo also auch jede Hitzewirkung ausgeschlossen war, und beschickte mit reichlichem Gewebssaft von jeder Drüse mehrere Agar- und Gelatineplatten, welche mindestens 3 Tage lang beobachtet wurden.

Ich muss dabei 2 Reihen von Versuchen unterscheiden. Bei der ersten verwandte ich Messer mit Holzgriffen, die ich ausglühte. Das Resultat war, dass von 43 Drüsen aus 20 Rindern ich nur 12 als steril bezeichnen konnte, da auf den übrigen Platten stets einzelne Colonieen von Subtilis und einer wurzelförmigen Bacillenart aufgingen. Wie sich nachträglich herausstellte, stammten diese Colonieen von den Messergriffen, von denen in Folge der Erbitzung und Abkühlung feine Theile los- 
gesprungen sein müssen, die noch keimfähige Sporen trugen. Von der 2. Reihe (58 Drüsen aus 25 Rindern) erhielt ich von 50 Drüsen sterile Platten, bei den anderen 8 waren Keime vorhanden, die aber lediglich als Verunreinigungen aufzufassen sind, schon aus dem Grunde, weil sie meist ganz oberflächlich lagen. Zu bedenken ist ferner, dass bei einer derartigen Arbeit eine beträchtliche Zahl von Verunreinigungen ganz unvermeidlich ist. Zunächst werden zuweilen beim Herausnehmen der Drüsen kleine, nicht sichtbare Einrisse entstehen, die während des weiten Transportes vom Schlachthofe zum Institute den durch die schmutzigen Schlächterhände und sonstwie auf die Oberfläche gebrachten Keimen ein Eindringen in die Drüsen ermöglichen. Da ohne Verletzung der Drüsenkapsel ein ganz sorgfâltiges Abpräpariren des Fettes nicht immer möglich ist, so spritzen beim Absengen oft Tröpfchen geschmolzenen Fettes herum und können, widerstandsfähige Sporen in noch keimfähigem Zustande enthaltend, auf die schon abgesengte Fläche fallen und dadurch $z$ verunreinigungen der Platten Veranlassung geben. Abgesehen von den allbekannten Verunreinigungen aus. der Luft, waren die gleichen Bakterienarten stets bei mehreren, am selben Tage verarbeiteten Drüsen zu finden, die zusammen in einem Gefäss befördert worden waren, was auch für die Natur der Colonieen als Verunreinigungen spricht. Stets waren die aufgegangenen Keime wenig zahlreich, während man bei einem Ursprunge aus dem Inneren der Drüsen sehr viele erwarten “müsste. Denn fände eine Durchwanderung der Darmwand mit dem Nahrungsfett statt, so müsste man entsprechend dem Keimgehalte des Darmes aus jeder Drüse zahllose Colonieen erhalten, vor allen Dingen das Bact. coli. Dieses wurde aber niemals beobachtet, ${ }^{1}$ obwohl jede entfernte Aehnlichkeit einer Colonie mit Bact. coli zur Weiterzüchtung Veranlassung gab. Die beobachteten Verunreinigungen waren: Subtilis, ein wurzelförmiger Bacillus, verschiedene Luftkokken, ein unbewegliches schlankes und ein auffallend dickes plumpes Stäbchen, eine Hefe, eine Proteusart, Sarcina lutea, Schimmel-Arten.

Von den 29 Kalbsdrüsen wurden 26 steril befunden, bei 3 zeigten sich Verunreinigungen, Heubacillen, das dicke Stäbchen und die Proteusart, wie sie bei den am gleichen Tage verarbeiteten Rindsdrüsen vorkamen. Entsprechend der geringeren Gefahr der Verunreinigungen bei den Kalbsdrüsen sind auch die Resultate günstiger. Die Drüsen wurden nämlich eingeschlossen in die Peritonealblätter befördert, und da bei den Kälbern in der Nachbarschaft der Drüse noch kein Fett abgelagert ist, so fällt auch diese Gefahr der Verunreinigung fort. Ich stehe also nicht untersucht.

1 Von jeder Colonie wurden gefärbte Ausstrichpräparate und hängende Tropfen 
an zu behaupten, dass die Gekröse-Drüsen bei Rindern normaliter keine Bakterien enthalten, d. h., dass ron einer Darmdurchwanderung der Bakterien während der Verdanung keine Rede sein kann. ${ }^{1}$

Im selben Sinne sind die Untersuchungen des Chylus, den ich durch Katheterisirung des Ductus thoracicus gewann, ausgefallen. Auf dieses. Verfahren musste ich aus äusseren Gründen leider bei Kälbern verzichten, obwohl es sehr wünschenswerth wäre, wegen des Vergleiches mit. menschlichen Säuglingen (Darmsepsis!) gerade junge Thiere heranzuziehen.

Dagegen untersuchte ich mit gütiger Unterstützung des Hrn. Privatdocent Dr. Kühnau den Chylus ron 5 Hunden und fand denselben auch bei Anwendung anaëroben Cultur-Verfahrens absolut steril, trotzdem die Hunde 3 Stunden vor der Operation gefüttert worden waren. Wegen der grossen Schwierigkeiten, bei jungen und kleinen Thieren den Ductus thoracicus aufzufinden und eine Canüle einbinden zu können, gelang mir diese Operation nur bei einer 3 Wochen alten Ziege. Von dem aus derselben gewonnenen Chylus wurden:

1) 5 Pl. neutrales Agar,

2) $5 \mathrm{Pl}$. Glycerinagar,

3) 5 Röhren mit Traubenzuckeragar in hoher Schicht

beschickt, und die ersteren bei $22^{\circ}$, die letzteren beiden bei $37^{\circ}$ gehalten. Ausser 2 Schimmelcolonieen auf einer der neutralen Agarplatten und 1 Col. Luftkokken auf einer Glycerin-Agarplatte waren sämmtliche Platten und Röhrchen noch nach 3 Tagen völlig steril.

Um die Frage des agonalen Durchganges ron Bakterien durch die Darmwand zu studiren, wiederholte ich einen Theil der Versuche von Wurtz und Béco.

Ich vergiftete Kaninchen durch subcutane Application von Natrium arsenicosum und Tartarus stibiatus und Sondenfütterung mit einer 1 proc. Lösung von Cantharidin in Oel. ${ }^{2}$

Die Kaninchen wurden meist sofort nach dem Tode - während des Agons wurde alles vorbereitet - abgezogen, die Pfoten abgeschnitten und das Fell am Kopfe abgetrennt. Der Kopf blie $b$ bei einem Theile der Thiere am Körper, um ein Eindringen von Keimen durch die eröffneten Halsgefässe zu verhüten. Die so vorbereiteten und auf ein Brett aufgespannten Thiere brachte ich in einen anderen Raum, um Verunreini-

1 Die Schlachtthiere waren am zeitigen Morgen vor dem Schlachten meist noch gefüttert worden, dementsprechend enthielten die meisten Drüsen sehr reichlich Chylus.

${ }^{2}$ Die Lösung ist nicht vollständig, ein Theil des Canthàridins bleibt in Suspension. 
gungen durch herumfliegende Haare etc. zu vermeiden. Dort wurde mit dem Paquelin der ganze Thorax und ein Theil des Abdomens abgesengt und mit ausgeglühten und abgekühiten Instrumenten Thorax und $A b$ domen eröffnet und die Organe herausgenommen. Herz, Blut, Urin und eventuell rorhandene Höhlenflüssigkeiten sog ich mit sterilen Pipetten in möglichst grossen Mengen - meist waren es mehrere Cubikcentimeter auf, die Gallenblase wurde im Ganzen abgetrennt und erst in einer PetriSchaale erōffnet. Milz, Nieren und Mesenterialdrüsen wurden stets gänzlich, von der Leber mehrere Cubikcentimeter grosse Stücke vom Rande und aus der Tiefe in zerkleinertem Zustande in die Nährmedien gebracht. Um eine Verunreinigung der zu zweit herausgenommenen Niere zu vermeiden, präparirte ich von der anderen Seite her das Peritoneum von der Wirbelsäule $a b$ und holte sie so extraperitoneal unter den Därmen hinweg, heraus.

Die Resultate sind in der folgenden Tabelle enthalten:

\section{Sectionen von vergifteten Thieren.}

1. Kaninchen, $1155^{\mathrm{grm}}$, erhält $1^{\mathrm{eem}} 1$ procent." Lösung ron Natr. arsenicosum subcutan. Tod nach $3 \frac{1}{2}$ Stunden.

Sterile Section sofort nach dem Tode. Platten, theils Agar, theils Gelatine, von linker Niere, Milz, Herzblut und Leber nach 3 Tagen bis auf 2 keimfrei. Die beiden Platten zeigten eine oberflächliche porzellanweisse Colonie von Luftkokken bezw. 4 oberflächliche Colonieen von Luftkokken und 1 von Sarcina lutea.

2. Kaninchen, $450 \mathrm{grm}$, bekommt 0.05 der Lösung ron Natr. arsenicosum. Tod nach $3^{1} / 2$ Tagen.

Sterile Section unmittelbar nach dem Tode. Platten von Galle, Leber, Herzblut, linker Niere, rechter Niere und Urin angelegt. Nach 3 Tagen Platten von Galle, Leber, Herzblut, Urin steril. Ferner 1 Pl. Herzblut 2 oberflächliche Colonieen, rechte Niere (2 Pl.) je 1 oberflächliche Colonie, linke Niere, 1. Pl., 1 oberflächliche Colonie, 2.Pl. 40 Colonieen verschiedener Bakterien, Milz 4 oberflächliche Colonieen.

3. Kaninchen, $485^{\mathrm{grm}}$, erbält 0.1 der 1 procent. Lösung subcutan. Tod nach $2 \frac{1}{2}$ Tagen.

Sterile Section sofort nach dem Tode. 2 Pl. Herzblut, 2 Pl. Leber, $1 \mathrm{Pl}$. Galle, $1 \mathrm{PI}$. Urin, $2 \mathrm{Pl}$. linke Niere, $1 \mathrm{Pl}$. rechte Niere, $1 \mathrm{Pl}$. Mesenterialdrüse steril, $1 \mathrm{Pl}$. Milz 1 Colonie Heubacillen.

4. Kaninchen, $1030^{\mathrm{grm}}$, erhält $0 \cdot 25$ der 1 procent. Natr. arsenicosumLösung. Tod nach 2 Tagen.

Sterile Section sofort nach dem Tode. 2 Pl. Blut, 3 Pl. Urin, 1 Pl. Galle, $1 \mathrm{Pl}$. Leber, $1 \mathrm{Pl}$. Milz, $1 \mathrm{Pl}$. rechte Niere steril, $1 \mathrm{Pl}$. Leber 1 oberflächliche Colonie von Kokken in Tetradenform, 1 Pl. linke Niere 1 oberflächliche Colonie von Kokken in Tetradenform, 1 Pl. Blut 1 Colonie Heubacillen. 
5. Kaninchen, $1040^{\mathrm{grm}}$, erhält $0.3^{\mathrm{ccm}} 1$ procent. Natr. arsenicosumLösung. Tod nach 30 Stunden.

Sterile Section sofort nach dem Tode. 2 Pl. Herzblut, 2 Pl. Urin, $2 \mathrm{Pl}$. rechte Niere, $1 \mathrm{Pl}$. linke Niere, $1 \mathrm{Pl}$. Ascites, $1 \mathrm{Pl}$. Milz, $2 \mathrm{Pl}$. Mesenterialdrüse, $1 \mathrm{Pl}$. Leber steril, $1 \mathrm{Pl}$. Urin 2 oberfächliche Keime (Subtilis), $1 \mathrm{Pl}$. Leber 1 Colonie Subtilis.

6. Kaninchen, $1935^{\mathrm{grm}}$, erhält $5^{\mathrm{ccm}} 1$ procent. Tart. stibiatus. Tod nach $2 \frac{1}{2}$ Tagen.

Section am Morgen nach dem Tode. Das Kaninchen war sofort nach dem Tode kaltgelegt worden und am Morgen steif gefroren. Resultat: 3 Pl. Blut (Herz), 1 Pl. Galle, 3 Pl. Leber, 1 Pl. Milz steril, 3 Pl. Harn, 2 Pl. rechte Niere, 2 Pl. linke Niere, 2 Pl. Mesenterialdrüsen übersät mit Bact. coli-Colonieen.

7. Kaninchen, $1260^{\mathrm{grm}}$, bekommt $1.0^{\mathrm{cm}} 1$ procent. Tart. stibiatusLösung $2 \mathrm{Mal}$ subcutan an 2 Tagen hinter einander. Tod $2 \frac{1}{2}$ Tage nach der ersten Injection.

Sterile Section sofort nach dem Tode. 3 Pl. Leber, 2 Pl. rechte Niere, 1 Pl. linke Niere, 1 Pl. Milz, 1 Pl. Ascites, 1 Pl. Mesenterialdrüse, 3 Pl. Blut, 2 Pl. Harn steril; 1 Pl. Galle 1 oberfächliche Colonie Luftkokken, 1 Pl. Harn desgl., 1 Pl. Niere 3 oberflächliche Keime.

8. Kaninchen, $970 \mathrm{grm}$, bekommt $0.8^{\mathrm{ccm}}$ der 1 procent. Lösung von Tart. stib. $2 \mathrm{Mal}$ im Zwischenraum von 24 Stunden. Tod 3 Tage nach der ersten Injection.

Sterile Section sofort nach dem Tode. 1 Pl. Urin, 1 Pl. Galle, 1 Pl. Milz, 1 Pl. Mesenterialdrüse, $2 \mathrm{Pl}$. linke Niere, $1 \mathrm{Pl}$. rechte Niere, $2 \mathrm{Pl}$. Leber, 2 Pl. Blut steril; 1 Pl. Urin 2 oberflächliche Colonieen, 1 Pl. rechte Niere 2 oberflächliche Colonieen, $1 \mathrm{Pl}$. Blut 1 oberflächliche Colonie.

9. Kaninchen, $1100^{\mathrm{grm}}$, bekommt $3^{\mathrm{cem}} 1$ Procent Cantharidin nicht ganz in Lösung enthaltenden Olivenöls mit Schlundsonde in den Magen. Tod nach 27 Stunden. Blase leer, Darm schwappend gefullt und stark injicirt, kein Ascites.

Aseptische Section $1 \frac{1}{4}$ Stunde post mortem d. 15. II. Resultat: $3 \mathrm{Pl}$. Blut, 1 PI. Galle, 2 Pl. Milz, 2 Pl. Leber, 2 Pl. rechte Niere, 1 Pl. linke Niere, 1 Pl. Mesenterialdrüse steril; 1 Pl. Leber (Ag.), 1 Pl. rechte Niere Ag. verunreinigt durch Heubacillen, die Colonie war bei der Platte von der Niere vom Rande ausgegangen. $1 \mathrm{Pl}$. linke Niere (Gel.) 1 verflüssigende Colonie entfernt vom Organ, 1 Pl. Gelatine von dem Tropfen trüben Blaseninhalts etwa 150 Col. eines unbeweglichen Stäbchens. (Bei der Entnahme war die versehentlich nicht ganz abgekühlte Pincette an eine Darmschlinge angeklebt. Möglich, dass also die hier gefundenen B. aus dem Darm direct stammen.)

10. Kaninchen. Vor Beginn des Versuches 1600 , beim Tode $1120 \mathrm{grm}$, bekommt $1 \frac{1}{2} \mathrm{cem}$ Cantharidinöl, später noch einmal $3^{\mathrm{cm}}$. Tod nach 5 Tagen am Abend. Sofort in's Kalte gelegt, Temperatur $-1^{\circ}$, am nächsten Morgen secirt. Darm matsch, in Peritoneum und Pleura keine Flüssigkeit, Blase leer. Resultat: 1 Pl. Galle, 2 Pl. rechte Niere, 2 Pl. linke Niere, 3 Pl. Herzblut, $1 \mathrm{Pl}$. Milz, $3 \mathrm{Pl}$. Leber, $2 \mathrm{Pl}$. Mesenterialdrüsen, $1 \mathrm{Pl}$. Pfortaderblut 
Durchgängigkeit von Darm Und Nieren für Bakterien. 519

steril; $1 \mathrm{Pl}$. Milz (Agar) 1 Colonie entfernt vom Organ, $1 \mathrm{Pl}$. Leber 5 Colonieen entfernt vom Organ, 1 Pl. Pfortaderblut 1 Colonie beweglicher, nicht verflüssigender Stäbchen.

Ich bin also nicht in der Lage, die Erfahrungen von Wurtz und Béc o, die sie mit denselben Mitteln gemacht haben, zu bestätigen, sondern muss betonen, dass auch vergiftete Thiere, die länger als 24 Stunden nach der Verabreichung des Mittels gelebt haben, für gewöhnlich sterile Organe haben, wenn nur die Section aseptisch und schnell genug gemacht wird. Das einzige Mal, wo sich Bakterien in den Organen fanden, hatte das Thier einige Zeit gelegen und wenn es auch sofort nach dem Tode in eine Umgebung von $-3^{0}$ Lufttemperatur gebracht wurde und am Morgen steif gefroren war, so muss ich doch, nach dem Befunde bei den anderen Thieren, annehmen, dass es sich hier um eine postmortale Wanderung handelt.

Merkwürdig ist, dass Leber, Galle, Milz und Blut frei von Keimen sind, während die Nieren, Mesenterialdrüsen und der Urin ausserordentlich zahlreiche Bakt. col. enthalten. Eine andere Erklärung als directe Wanderung durch die Darmwände nach den Drüsen, Nieren und der Blase hin ist wohl nicht möglich. Denn falls die Verbreitung auf dem Blutwege erfolgt wäre, müssten Blut und Milz doch auch das Bakt. col. enthalten. Die Gallenwege können hier nicht als Eingangspforte gedient haben. Der Fall ist hervorragend geeignet, zu zeigen, wie schnell das Eindringen von Keimen postmortal erfolgen kann, auch bei niederer Temperatur, und wie weit wir noch davon entfernt sind, eine Erklärung für die Bedingungen, unter denen die Leichenphänomene sich entwickeln, geben zu können. Die Möglichkeit einer schnellen postmortalen Einwanderung der Bakterien in die Organe und die Blutbahn ist auch durch die Versuche Hauser's, Birch-Hirschfeld's, Chvostek's (ich meine die zahlreichen positiven Befunde bei den 12 Stunden nach Tödtung durch Genickstich untersuchten Mäusen) erwiesen, und es ist wohl möglich, dass in Folge der Alteration der Darmwand die Infection des Organismus nach dem Tode wesentlich schneller erfolgt, als Trombetta für seine Versuchsthiere feststellen konnte. Damit wird auch die Erwägung Beco's hinfällig, dass, da nur dann schnell Leichenfäulniss eintreten soll, wenn eine agonale Einwanderung stattgefunden hat, diese ein häufiges Vorkommniss sei. Ich kann also nicht der Béco'schen Behauptung beistimmen, dass es mit Sicherheit (à cuup sûr) möglich wäre, die Verbreitung von Mikrobien im Organismus hervorzurufen. Im Gegentheil muss betont werden, dass es weder nach den Litteraturangaben noch nach den hier neu berichteten Versuchen möglich ist, auch nur annähernd ein Urtheil darüber abzugeben, ob es überhaupt vorkommt, dass Bakterien ohne 
intensive Verletzung der Darmschleimheit dieselbe während des Lebens zu durchdringen vermögen oder nicht. Alle die positiven Befunde, die thatsächlich z. B. von Achard und Phulpin, Wurtz, Béco, Chrostek und Egger u. A. berichtet werden, sind, wenn wir sie zunächst als einwandsfrei betrachten wollen, durchaus noch nicht beweisend für die Durchgängigkeit des Darmes. Die Seite 9 der Arbeit von Chvostek und Egger angezogenen Bakterienbefunde im Blute nach Injectionen mit Papayotin (Rossbach) und Jequirityextract (Dirking, Holmfeld und Solomonson) haben nicht die mindeste Beweiskraft für eine Infection vom Darme aus, noch viel weniger diejenigen ron Wyssokowitsch (115) u.s. w., die sich lediglich damit begnügen, die Möglichkeit einer künstlichen Verminderung der Widerstandsfähigkeit des Organismus festzustellen. Ein Theil der am Menschen positiv ausgefallenen Cntersuchungen dürfte mit Sicherheit auf eine terminale Sepsis zurückzuführen sein, z. B. die Fälle von Achard und Phulpin mit Decubitus, Septicämie, Diabetes, eitriger Pyelonephritis, Lungentuberculose, zumal auch sonst zahlreiche Streptokokkenbefunde im Blute von Phthisikern bekannt sind. Dass wir dabei einen häufigeren positiven Befund auch in Leber und Milz erwarten dürfen, ist durch Wyssokowitsch (114) nachgewiesen worden, der zeigte, dass diese Organe eine Ablagerungsstätte für Bakterien ebenso wie für andere corpusculäre Elemente bilden.

Ein anderer Theil findet eine befriedigende Erklärung in der Annahme einer Infection von den Lungen aus, deren Modus von Wyssokowitsch (115), Grammatschnikoff (40) und von Buchner (17) auch in seinem Verhältnisse zur Infection vom Darme aus eingehend besprochen wird. Bei benommenen Kranken werden ja bekanntermassen in den letzten Stunden ausserordentlich häufig Massen aspirirt, die dann eben zu einer Infection des Kreislaufes führen können. Nicht zu vergessen sind auch als mögliche Eingangspforte die Tonsillen. Die Annahme Chrostek's, dilss ein Ausgehen der Infection von solchen Stellen nur selten vorkäme, kann ich nicht als genügend begründet ansehen. Im Gegentheil scheinen gerade die Widersprüche zwischen negativen Befunden während des Lebens und postmortalen positiven, die er auf Seite 8 anführt, zu beweisen, dass thatsächlich von anderen erkrankten Körperstellen aus unmittelbar nach dem Tode eine schnelle Ausbreitung von Infectionserregern stattfinden kann. Denn nur so werden die Beobachtungen von Petruschky (78), der in 8 von 14 Fällen von Tuberculose Streptokokken nach dem Tode im Blute fand, während des Lebens nur ein Mal und ron Frosch (34) verständlich, der sogar Diphtheriebacillen bei 10 von 14 Fällen im Blute postmortal nachwies, während des Lebens nie. 


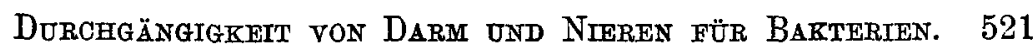

Ein drittes Moment, welches den Werth der positiven Befunde herabzusetzen geeignet ist, bildet die Thatsache, dass der Tod der verschiedenen Gewebe nicht gleichzeitig erfolgt. Der Oesophagus z. B. ist häufig schon während der letzten Stunden völlig schlaff und todt. Warum soll nicht auch der Darm in manchen Fällen eher dem Tode verfallen, als das Herz? Dass abgestorbene Schleimhaut, wenn sie auch unter dem Mikroskope völlig intact erscheint, der Einwanderung der Bakterien ein Hinderniss entgegensetzte, fällt mir natürlich nicht ein, zu behaupten. Der Nachweis ist allerdings direct nicht zu führen, da es uns auch dureh das Mikroskop nicht möglich ist, frisch abgestorbenes Gewebe mit Sicherheit von lebendem zu unterscheiden. Jedem Chirurgen ist ferner die Thatsache bekannt, dass bei eingeklemmten Hernien der Darm noch lebensfrisch aussehen und trotzdem nach der Reposition der Nekrose anheimfallen kann, ein Beweis dafür, wie schwer das Gewebe geschädigt worden ist. Dass unter solchen Umständen eine Durchwanderung von Bakterien stattfinden kann, ist natürlich wicht zu bestreiten und deshalb ist auch der Nachweis von Bakterien in der Darmwand ${ }^{1}$ und im Bruchwasser nicht beweisend für eine Durchgängigkeit der Darmwand schon bei geringen Störungen, abgesehen davon, dass auch hier die negativen Berichte erheblich grösseren Werth besitzen als die positiven.

Damit komme ich zu dem letzten Punkte. Denn selbst auf die Gefahr hin, von Béco gleich M. Neisser beschuldigt zu werden, dass unsere Technik noch in den Kinderschuhen stecke, muss ich Versuchsfehler für einen grossen Theil der positiven Befunde verantwortlich machen. Ich stelle mich ganz auf den Standpunkt $\mathbb{M}$. Neisser's und Hauser's, dass bei der Schwierigkeit der Technik und bei den zahlreichen Möglichkeiten der Verunreinigung negative Befunde ein ganz anderes Gewicht baben als positive. Ein sprechender Beweis dafür sind die gegensätzlichen Befunde im Chylus bei Nocard, Poreher und Dósonbry einerseits und M. Neisser und mir andererseits. Von den französischen Autoren wird leider nichts über die Technik angegeben. Da aber das von Heidenhain angegebene Verfahren der Einbindung einer Canüle in den Ductus thoracicus des lebenden Thieres kaum von ihnen benützt sein dürfte, so waren sie jedenfalls auf die in den Gefässen der Bauchböhle enthaltene Lymphe angewiesen und haben dadurch die positiven Resultate durch Verunreinigungen erbalten. Bei dem solchen Verunreinigungen viel weniger ausgesetzten Verfahren, welches von uns geübt wurde, ergaben sich bei den Thieren in nüchternem Zustande und während der Verdauung nur negative Resultate. Ich glaube, für jeden unbefangenen Beurteiler muss dies den Ausschlag geben.

\footnotetext{
i Boennecken, a. a. 0 .
} 
Das von Béco angerathene Verfahren, bei der Gefahr einer Verunreinigung die Oberfläche der Niere abzusengen und aus dem Inneren mit der Oese Gewebssaft zu holen, ist uns natürlich auch nicht unbekannt. Es kam uns aber darauf an, das ganze Organ in ein Nährmedium zu übertragen. Denn bei einem negativen Befunde nach Aussaat weniger Oesen Gewebssaft ist natürlich der Einwand sofort bei der Hand, dass spärliche Keime der Entdeckung entgangen sein könnten. Béco stützt ja darauf seine Annahme, dass auch in den Fällen, wo er bei Leichen die Milz steril fand, Bakterien dennoch vorhanden gewesen seien. Das Experiment, ganze Organe oder grosse Organstücke steril herauszunehmen und anfzubewahren, ist auch uns sehr geläufig. Nichtsdestoweniger wird jeder erfahrene Bakteriologe zugeben müssen, dass Verunreinigungen niemals mit ganz absoluter Gewissheit auszuschliessen sind; je complicirter die Versuche sind, um so weniger.

Im Uebrigen behauptet $\mathrm{N}$ eisser durchaus nicht, wie Béco annimmt, dass sämmtliche nicht sterile Sectionen nur durch Versuchsfehler zu erklären sind, sondern nur, "soweit nicht Darmperforationen oder andere mechanische Läsionen schwerster Art wirklich eine Passage der Bakterien veranlasst haben" (S. 24). Dass solche für einen Theil der Fälle wirklich in Betracht kommen, ist klar, denn auch bei den sterilen Seetionen waren schon Hämorrhagieen und Epithelabschürfungen im Darme festzustellen. Nebenbei ist ausdrücklich auf die Möglichkeit andersartiger Infectionen hingewiesen (S. 23).

Die Ausführungen Béco's sind, wie wir gesehen haben, nicht geeignet, die Folgerungen, welche sich aus Neisser's und meinen Untersuchungen ergeben, zu erschüttern und dem Darme eine irgendwie beträchtliche Rolle als Eingangspforte für Infectionen zuzuweisen. Ich muss im Gegentheile betonen, dass die Schutzkraft des Darmepithels in unserer Zeit vielfach unterschätzt wird. Nur für wenige Bakterien ist die Fähigkeit, in die Darmwand und durch dieselbe zu dringen, erwiesen, für die grosse Mehrzahl bildet die Darmwand sogar noch bei starken Alterationen ein unüberwindliches Hinderniss.

Nicht zu vergessen für die Beurtheilung der Durchgängigkeit des Darmes für Bakterien ist eine Thatsache, auf die Pfeiffer und Kolle (79) aufmerksam gemacht haben und die allein geeignet ist, die Anschauung ad absurdum zu führen, dass regelmässig oder auch nur häufiger Darmbakterien durch das Epithel hindurch in den Säftestrom gelangten. Es finden sich im Blute normaler Menschen keine Antikörper der Colibacillen. Dieselben treten aber sofort auf, wenn Abscesse oder andere Erkrankungen vorhanden sind, für die das Bact. coli verantwortlich zu machen ist. 
Nicht unwichtig ist ferner die Thatsache, dass von den 41 von Kühnau (60) aufgeführten Typhusfällen nicht ein einziger in seinem Blute Bakterien beherbergt, deren Ursprung im Darme zu suchen wäre. Dabei waren doch zum mindesten bei einem grossen Theile der Fälle Geschwũre im Darme vorhanden, ein weiterer Beweis für den grossen Widerstand, den selbst der geschädigte Darm dem Eindringen von Keimen entgegensetzt.

Die bisher bekannten Befunde' sind mit der Annahme einer postmortalen Wanderung oder einer wahren terminalen Infection aus anderen Quellen rollständig erklärt. Auch eine agonale Durchwanderung des Darmes ist nicht mit Sicherheit erwiesen. Mit aller Schärfe ist die Behauptung zurückzuweisen, dass schon geringe functionelle Störungen, wie etwa eine Hrperämie, die Darmwand für Bakterien durchlässig machen könnten.

Schon die tägliche Erfahrung lehrt uns ja auch, dass dies nicht der Fall ist. Jede Laparotomie bewirkt Hyperämieen des Darmes und bei der Reizung des Peritoneums durch in der Bauchböhle ausgeführte Manipulationen sind auch die übrigen Bedingungen erfüllt, die bei Einwanderung von Mikrobien zu einer Sepsis oder Peritonitis führen müssten (Boennecken). Wir sehen aber, dass septisehe Erkrankungen nach Laparotomieen jetzt selten geworden sind - etwa $5 \%$ - und dass diese Zahl durch immer grössere Verrollkommnung der Asepsis noch mehr herabgedrückt wird. Dies wäre natürlich bei Entstehung der Peritonitis oder Sepsis durch aus dem Darme ausgewanderte Mikroorganismen nicht in dem Grade möglich, wie es thatsächlich der Fall ist.

\section{Litteratur,}

die Durchgängigkeit des Darmes betreffend.

1. Achard et Phulpin, Contribution à l'étude de l'envahissement des organespar les microbes pendant l'agonie et après de la mort. Arch. de méd. expér. 1895. p. 25.

2. Alapy. Ref. Baumgarten. 1889. S. 510.

3. Arnd, Ueber die Durehgängigkeit der Darmwand eingeklemmter Brüche. Centralblatt für Bakteriologie. Bd. XIII. S. 324.

4. Arnold, Dntersuchungen üb. Staubinhalation u. Staubmetastase. Leipzig 1885.

5. Auspitz, Ueber die Resorption ungelöster Stoffe bei Sängethieren. Wiener med. Jahrbücher. 1871. Bd. III.

6. Barlow und Sittmann, Ueber einen Befund von Bact. coli im lebenden Blute. Deutsches Archiv für klin. Med. Bd. LII. Citirt nach Birch-Hirschfeld.

7. Béco, Étude sur la pénétration des microbes intestinaux dans la circulation géuérale pendant la vie. Annales de l'Institut Pasteur. 1895. p. 199.

8. Derselbe, La perméabilité de la paroi intestinale etc. Arch. de méd. expér. 1897. p. 108 . 
9. Bireh-Hirschfeld, Zur Beurtheilung des Bacterium coli commune als Krankheitserreger u. s. w. Inaug.-Diss. Leipzig 1896.

10. Bizzozzero, Ueber das constante Vorkommen von Bakterien in den Lymphfollikeln des Kaninchendarmes. Centralblatt für med. Wissenschaften. 1885. S.801. Ref. Banmgarten. 1885. S. 165.

11. Boennecken, Virchow's Archiv. Bd. CXX.

12. Bosc, Les lésions de l'intestin etc. Troisième Congrès Française de méd. int. 1896. Ref. Centralblatt für Balteriologie. Bd. XX. S. 687.

13. Bosc et Blanc, Les lésions de l'intestin dans les cas de hernie étrangée et d'engonement. Arch. de méd. expér. 1896. p. 723.

14. Bouchard, Revue de méd. expér.

15. Braunschweig, Ueber Allgemeininfection von der unverletzten Bindehaut aus. Fortschritte der Medicin. 1889. Ref. Baumgarten. 1889. S. 514.

16. Brentano, Ergebnisse bakteriol. Bruchwasser-Untersuchungen. Deutsehe Zeitschrift für Chirurgie. Bd. XLIII. - Centralblatt für Chirurgie. 1896. S. 823.

17. Buchner, Untersuchungen über den Durchtritt von Infectionserregern durch die intacte Lungenoberfläche. Archiv für Hygiene. Bd. VIII.

18. Derselbe, Beiträge zur Kenntniss des Neapeler Cholerabacillus. Ebenda. Bd. III. S. 361 .

19. Charrin, Compt. rend. de la Soc. biol. 1892. p. 995 . Citirt nach Chvo. stek und Egger.

20. Charrin et Veillon. Ebenda. 1893. p. 1057. Ref. Baumgarten. 1894. S.76.

21. Dieselben. Ebenda. 1894. Citirt nach Béco.

22. Chrostek, Uéber die Verwerthbarkeit postmortaler bakteriologischer Befunde. Wiener klin. Wochenschrift. 1896. Nr. 49.

23. Chvostek und Egger, Ueber die Invasion von Mikroorganismen in die Blutbahn während der Agone. Ebenda. 1897. Nr. 3.

24. Cornil. Citirt bei Lesage et Macaigne.

25. Czerny u. Moser, Klinische Beobachtungen an magendarmkranken Kindern im Säuglingsalter. Jahrbuch für Kinderheilkunde. Bd. XXXVIII.

26. Dallemagne, Contribution à l'étude des microbes du tube digestif des cadavres. Académie de méd. de Belgique. 1894. Citirt nach Béco.

27. Derselbe, Microbes du tube gastrointestinal des cadavres. Arch. de méd. expér. 1895. p. 274. Ref. Baumgarten. 1895. S. 603.

28. Desoubry. et Porcher, De la présence de microbes dans le chyle normal du chien. Compt. rend. Soc. biol. 1895. Ref. Baumgarten. 1895. S. 605.

29. Emmerich, Untersuchungen über die Pilze der Cholera asiatica. Archiv für Hygiene. Bd. III. S. $361 \mathrm{ff}$.

30. Falk, Ueber d. Verhalten d. Infectionsstoffe im Verdauungscanal. Virchow's Archiv. Bd. CVIII.

31. FischI, Ueber septische Infection des Sänglings. Zeitschrift f. Heilkunde. 1894. Ref. Centralblatt. Bd. XV. S. 765.

32. v. Fodor, Ueber Bakterien im Blute des gesunden Thieres. Baumgarten. 1885. S. 168 .

33. Derselbe, Bakterien im Blate lebender Thiere. Archiv für Hygiene. IV. Ref. Baumgarten. 1886. S. 375.

34. Frosch, Diese Zeitschrift. Bd. VIII.

35. Garré, Fortschritte der Medicin. 1886. Bd. IV. Ref. Baumgarten 1886. S. 385 . 
36. Garré, Zur Aetiologie acut-eitriger Entzündungen. Fortschritte der Medicin. 1885. Nr.6. Ref. Baumgarten. 1885. S. 26.

37. Gaston et Renard, Rev. mens. des malad. de l'enfauce. 1893. T. XI.

38. Gilbert et Lion, Contrib. à l'étude des bactéries intest. Sem. méd. 1893. Ref. Baumgarten. 1893. S. 291.

39. Gilbert et Fonrnier, Du xôle des microbes dans la génèse des calculs biliaires. Sem. méd. 1896. S. 61. - Hygienische Rundschau. 1896. S. 361.

40. Grammatschnikoff, Fortschritte der Med. 1893. Cit. nach Chvostek.

41. Hanot, Ictère grave hypothermique. Ref. Baumgarten. 1883. S. 166.

42. Hauser, Ueber das Vorkommen von Mikroorganismen im lebenden Gewebe gesunder Thiere. Archiv f. experimentelle Pathologie. Bd. XX. Ref. Baumgarten. 1885. S. 166.

43. Derselbe, Bakterienbefunde bei Leichen. Zeitschrift. für Heilkunde. Bd. XVIII. S. 421.

44. He ubner, Zeitschrift für klin. Medicin. Bd. XXIX.

45. Hil debrand, Experimentelle Untersuchungen über das Eindringen pathogener Mikroorganismen von den Isuftwegen und der Lunge aus. Beiträge zur pathol. Anatomie und Physiologie. Bd. II. S. 411. Ref. Jahrb. für die gesammte Medicin. 1889. Bd. I. S. 266.

46. Hirsch, Ein Fall von Streptokokken-Enteritis im Säuglingsalter. Centralblatt für Bakteriologie. Bd. XXII. S. 369.

47. Hueppe, Naturwissenschaftl. Einführung in die Bakteriologie. Wiesbaden 1896. Citirt nach Chvostek und Egger.

48. Israël, Klinische Beiträge zur Aktinomykose des Menschen. Berlin 1885. Ref. Baumgarten. 1885. S. 137.

48a. Kaensche, Diese Zeitschrift. Bd.XXII. S. 53.

49. Kamen, Zur Frage der Tetanusformen nicht traumatischen Ursprunges. Centralblatt für Bakteriologie. Bd. XVIIL. S. 513.

50. K arlínsky, Ein Beitrag zur Frage der Puerperalinfection des Neugeborenen. Ref. Ebenda. Bd. VI.

51. Karlinski, Eine seltene Darmtyphus-Complication. Berliner klin.Wochenschrift. 1888. Nr. 43. Ref. Baumgarten. 1888. S. 149.

52. Ka ufmann, berichtet über Porcher et Desoubry. Sem. méd. 1896.

53. . Klecki, Recherches sur la pathogénie de la peritonite d’origine intestinale. Annales de l'Institut Pasteur. 1895. Ref. Baumgarten. 1895. S. 306.

54. Klem m, Studien über die pathol.-anatom. Veränderungen am Darm in Folge von Brucheinklemmung. Inaug.-Diss. Dorpat 1889. Cit. nach Neisser.

55. Kocher, Die acute Osteomyelitis mit besonderer Berücksichtigung ihrer Ursachen. Deutsche Zeitsehrift für Chirurgie. Bd. XI. Cit. nach Neisser.

56. Kocher und Tavel, Vorlesungen über chirurg. Infectionskrankheiten. BaselLeipzig 1895. Ref. Baumgarten. 1895. S. 13.

57. A. P. Korkanoff, Zur Frage von der intestinalen Infection. Archiv für Hygiene. Bd. X. S. 485.

58. Kraft. Ref. Centralblatt für Chirurgie. 1892.

59. Kruse in Flügge, Die Mikroorganismen. I. S. 316 .

60. Kühna u, Ueber Resultate nnd Leistungsfähigkeit der bakteriol. Blutuntersuchung. Diese Zeitschrift. Bd. XXV. S. 492.

61. Lesage et Mecaigne, Contribution à l'étude de la virulence du Bact. coli. Archiv de méd. expér. 1892 . p. 350. 
62. Létien ne, Recherches bactériologiques sar la bile humaine. Archiv de méd. expér. 1891. p. 761.

63. Libman, Weitere Mittheilungen zur. Streptokokken-Enteritis im Säuglingsalter. Centralblatt für Bakteriologie. Bd. XXII. S. 376.

64. Lion et Marfan, Deux cas ete. Ref. Ebenda. Bd. XII. S. 336.

65. Macklezew, Zur Frage der Durchgängigkeit der Darmwand für Bakterien kei Darmverschluss. Wratsch. 1897. Nr. 10. Ref. Centralblatt für Bakteriologie. Bd. XXI. S. 939.

66. Malvoz, Le bact. coli comm. etc. Arch. de méd. expér. T. III. Nr. 5.

67. Derselbe, La putréfaction. Sealpel 1895. Cit. nach Béco.

68. Derselbe, Recherches bactér. de la fièrre typhoide. Liège 1893. Cit. nach Chrostek u. Egger.

69. Manfredi. Ref. Baumgarten. 1886. S. 376 .

70. Marfan et Lion, Compt. rend. Soc. biol. 1891. Ref. Baumgarten. 1891. S. 280.

71. Marfan et Marot, Rev. mens. des malad. de l'enf. 1893. Citirt nach Neisser.

72. M. Neisser, Ueber die Durchgängigkeit der Darmwand für Bakterien. Diese Zeitschrift. Bd. XXIL. S. 12.

73. Nepveu. Ref. Fortschritte der Medicin. Bd. I. S. 642. Cit. bei Garré.

74. Nocard, Influence des repas sur la pénétration des microbes dans le sang. Sem. méd. 1895. p. 63.

75. Oker-BIom, Beitrag zur Kenntniss des Eindringens des Bacterinm coli in die Darmwand bei pathol. Zuständen. Centralblatt für Bakteriologie. Bd. XV.

76. Orloff, Materiale zur Frage über die Eintrittswege der Mikroben in den thierischen Organismus. Baumgarten 1887.

77. Pawlowsky, Virchow's Archiv. Bd. CXVII. S. 469. Ref. Baumgarten. 1887. S. 389 .

78. Petruschky, Deutsche med. Wochenschr. 1893. Nr.14. Cit. n. Chvostek.

79. Pfeiffer u. Kolle, Diese Zeitschrift. Bd. XXI. S. 235.

80. Ponfick, Ueber die Entstehnngs- und Verbreitungswege der acuten Miliartuberculose. Berliner klin. Wochenschrift. 1887. Cit. nach Neisser.

81. Porcher et Desoubry, De la présence des microbes dans le sang de la circulation générale chez le chien. Compt. rend. Soc. biol. 1895. Cit. nach Béco.

82. Posner, Infection und Selbstinfection. Berliner Klinit. H. 85. Cit. nach Neisser.

83. Posner und Lewin, Ueber kryptogenetische Entzündungen gamentlich der Harnorgane. Berliner klin. Wochenschrift. 1895.

84. Rénon, Passage du mycèle de l’Aspergillus etc. Sem. méd. 1896. Nr. 26. - Centralblatt füir Bakteriologie. 1896.

85. Ribbert, Ueber das Vorkommen von Spaltpilzen in der normalen Darmwand des Kaninchens. Deutsche med. Wochenschrift. 1885. Ref. B a umgarten. 1885. S. 165.

86. Ritter, Ueber die Darchgängigkeit der Darmwand. Inaug.-Diss. Göttingen 1890. Cit. nach Neisser.

87. Roosing, Zur Frage, ob sich die Mikroorganismen hauptsächlich im Bruchwasser vorfinden. Centralblatt für Chirurgie. 1892. S. 649. Cit. nach Neisser.

88. Rossbach, Centralblatt für die med. Wissenschaften. 1882. Cit. b. Hauser.

89. Roth, Ueber das Verhalten der Schleimhäute u. s. w. Diese Zeitschrift. Bd. IV. 
Dubchgängigkeit von Darm und Nigren für Bakterten. 527

90. Salomonson und Dircking-Holmfeld, Fortschritte der Medicin. II. Cit. nach Chrostek-Egger.

91. Sauchez, Troledo et Veillon, De la présence du bac. de tétanos etc. Sem. méd. T. X. Ref. Baumgarten. 1891. S. 218.

92. Serestre, Sitzungsberichte des Soc. méd. des hôpitaux. Paris 1887. Cit. nach $\mathrm{Neisser}$.

93. Schl offer, Bakteriologische Bruchwasseruntersuchungen u. s. w. Beiträge zur kelin. Chirurgie. 1895. Bd. XIV. Ref. Baumgarten. 1895. S. 71.

94. Schnitzler, Chir. bakteriol. Mittheilungen. Ref. Centralblatt f. Bakteriologie. Bd. XV. S. 667 .

95. Sordoillet, Péritonide sans perforation. Ref. Ebenda. Bd. XVI.

96. Sruday et Bodin, Infection colibacillaire généralisée au cours de la grippe. Sem. méd. 1895. Nr. 26. - Centralblatt für Bakteriologie. Bd. XVIII. S. 132.

97. Stern, Klin. bakteriol. Beiträge zur Pathologie u. Therapie des Abdominaltyphus. Sammlomg klin. Vorträge. Neve Folge. Nr. 138. Ref. Baumgarten. 1895. S. 290.

98. Tavel u. Lanz, Ueber die Aetiologie der Peritonitis. Mittheilungen aus Kliniken und med. Instiluten der Schweiz. 1893. Cit. nach Neisser.

99. Teissier, Contribution à l'étude du tetragène. Arch. de méd. expér. 1896. p. 14.

100. Thiemich, Inaug.-Diss. Breslau 1894. Ref. Baumgarten. 1894. S. 266. 101. Tietze, Klinische und experimentelle Beiträge zur Lehre von der Darmincarceration. Habilitationsschrift. Breslau 1894. Cit. nach Neisser.

102. Trombetta, Centralblatt für Bakteriologie. 1891. Bd.X. S. 664.

103. Veillon et Jayle, Compt. rend. de Soe. biol. 1891. Ref. Baumgarten. 1891. S. 292.

104. Wasmuth, Ueber die Durehgängigkeit der Hant für Mikrobien. Centralblatt für Bakteriologie. Bd. XII. S. 824 a. 846 .

105. Wassilieff-Kleimann, Ueber Resorption körniger Substanzen von Seiten der Darmfollikel. Archiv für exper. Pathologie. Bd. XXVII. Cit. nach Neisser. 106. Weintrand, Untersuchungen über Kohlenstaub-Metastasen. Inaug.-Diss. Strassburg 1889. Cit. nach Neisser.

107. Welch, Conditions underly in the infection etc. Americ. Journ. of the med. sc. 1891. Ref. Baumgarten. 1891. S. 43.

108. Wreden, Zur Aetiologie der Cystitis. Centralblatt für Chirurgie. 1893. Ref. Baumgarten. 1893. S. 314.

109. Wurtz et Herman, De la présence fréquente du bact. coli dans les cadavres. Arch. de méd. exper. 1891. S. 753.

110. Wurtz, Compt. rend. Soc. biol. 1892. p. 992 đ. 1011. Cit. nach Béco.

111. Derselbe, Le coli bacille. Arch. de méd. expér. 1893.

112. Wurtz et Hudélo, De la pénétration des bactéries intestinales dans le péritoine et dans le rang pendant l'intoxication alcoolique. Sem. méd. 1895. Nr. 6. - Hygienische Rundschau. "1895. S. 601.

113. Welch, s, oben 107.

114. Wyssokowitsch, Ueber die Schicksale der in's Blut injicirten Mikroorganismen im Körper der Warmblüter. Diese Zeitschrift. Bd. I. S. 1.

115. Derselbe, Centralblatt für Bakteriologie. 1889. S. 413.

116. Z a bor, Untersuchungen über das Vorkommen von Spaltpilzen im normalen Thierkörper. Ref. Baumgarten. 1887. 
117. Ziegler, Lehrbuch der pathol. Anatomie. Jena 1892.

118. Derselbe, Untersuchungen über die intestinale Form der Peritonitis. München 1893. Ref. Baumgarten. 1893. S. 619.

119. Zweifel, Giebt es im gesunden Organismus Fänlnisskeime? Ref. Baumgarten. 1885. S. 167.

\section{Durchgängigkeit der Niere.}

In innigem Zusammenhange mit der Frage der Durchgängigkeit des Darmes für die Bakterien steht diejenige nach der Ausscheidung im Blute. befindlicher Bakterien durch drüsige Organe. Nimmt man, wie es in letzter Zeit häufig geschehen ist, an, dass ein Debertritt von Darmbakterien in die Körpersäfte häufig vorkommt, so ergiebt sich daraus die Forderung, die Wege zu erforschen, auf denen sie den Körper wieder verlassen. In der That haben sich denn auch die Stimmen gemehrt, die im Gegensatz zu der besonders von Wyssokowitsch begründeten und noch heute von. Vielen festgehaltenen Ansicht behaupten, dass die Ausscheidung von Bakterien in Harn, Galle und Schweiss durchaus nichts Seltenes sei, sondern sogar auf einer physiologischen Thätigkeit der Excretionsorgane beruhe.

Betrachten wir uns die Verhältnisse einmal genauer. Von vornherein lässt sich nicht annehmen, dass im Speichel und Schleim Bakterien ausgeschieden werden sollten. Viel eher könnte dies erwartet werden vom Urin, ferner auch von Galle und Schweiss, von denen die beiden letzteren wenigstens theilweise Auswurfstoffe, Excrete, darstellen; vielleicht könnte auch eine Abscheidung nach dem Darme vorausgesetzt werden.

Rufen wir uns zur Klärung der Sachlage den Vorgang der Secretion, bezw. Excretion zurück. Nach den feststehenden Lehren der Physiologie handelt es sich bei der Secretion darum, dass aus dem Blute durch die specifische Thätigkeit der Drüsenepithelien bestimmte Stoffe aus dem Gesammtblute aufgenommen und meist nach chemischer. Umwandlung als die wirksamen Bestandtheile der betreffenden Drüsen in das Innere derselben abgeschieden werden. Dabei muss man das Vorhandensein chemischer Affinitäten zwischen den Drüsenepithelien und den betreffenden chemischen Körpern voraussetzen. Die Möglichkeit, dass solche chemische Affinitäten auch eventuell zu giftigen Körpern, die in das Blut gelangt sind, einmal statthaben und dass dieselben also auch einmal in den Secreten wieder erscheinen können, ist ohne Weiteres zuzugeben. Man wird aber dann eben nicht mehr von physiologischer Ausscheidung sprechen können, da ja dann von "Secretion" dem Wesen nach füglich nicht mehr die Rede sein kann, sondern nur von einem pathologischen Vorgange. 
Insofern nicht ganz besondere chemische Verhältnisse vorliegen, werden die Epithelien der Secretionsorgane überhaupt nicht mit in die Blutbahn gebrachten giftigen Stoffen oder gar mit geformten Elementen, wie sie die Bakterien darstellen, in Berührung kommen, geschweige denn eine physiologische Excretion derselben bewirken. Nur unter exquisit pathologischen Bedingungen, d. h. wenn etwa dureh den Diffusionsstrom die Drüsenzellen vergiftet würden, könnten in Secreten Gifte oder gar Bakterien erscheinen, indem sie durch die oder zwischen den widerstandsunfähig gewordenen Zellen hindurch wandern.

Wesentlich anders liegen die Verhältnisse in den Excretionsorganen. Dieselben sind bestimmt, unter normalen Verhäitnissen die für den Körper überflüssigen und schädlichen Stoffe aus demselben zu entfernen. Damit dies möglich ist, müssen natürlich die Drüsenepithelien mit der Gesammtmenge der Blutflüssigkeit in Berührung kommen, und ihre Aufgabe besteht darin, aus dieser Gesammtmenge die rorgebildeten Auswurfstoffe zurückzuhalten und sie auf die innere Oberfläche abzuscheiden. Hier ist also die Möglichkeit einer physiologischen Excretion chemischer Körper und eventuell auch geformter Elemente zuzugeben. Wenn dieselbe den Namen einer "physiologischen Ausscheidung" in Wahrheit verdienen soll, müssen demnach verschiedene Bedingungen erfüllt sein. Die normalen Nieren müssen, entsprechend dem Vorgange bei der Harnstoff- u. s. w. Ausseheidung, in's Blut gelangte körperliche Elemente oder Bakterien in einer Weise aus dem Kreislauf entfernen, die sich - natürlich innerhalb gewisser Grenzen - für dieselbe Thierart und dieselben Körper in bestimmtem Typus regelmässig wiederholt. Die einmal begonnene Ausscheidung müsste andauern, bis die im Blute kreisenden Elemente auf eine Zahl herabgemindert wären, die, wenn ursprünglich rorhanden, die Secretion nicht anregen kann. Anderenfalls müsste man ja annehmen, dass eine Schädigung der Auscheidungsorgane entstanden wäre, die eine weitere secretorische Thätigkeit verhinderte, dass es sich also nicht um einen "physiologischen" Vorgang gehandelt haben könnte. Zu einer physiologischen Function gehört implicite ein gewisser Zweck, und dieser kann hier nur darin bestehen, den Körper von fremden, eventuell schädlichen Elementen zu befreien. Daher wird auch auf das zeitliche Element ein gewisser Werth zu legen sein; indessen könnte man annehmen, dass die Ausscheidungsorgane einer gewissen Zeit bedürften, um sich an die ungewöhnliche Aufgabe der Ausscheidung körperlicher Elemente zu gewöhnen. Auch die Menge der ausgeschiedenen Bakterien ist ohne Zweifel von Belang. Denn man wird erwarten dürfen, dass nach Analogie der von den Nieren ausgeschiedenen gelösten Stoffe sich die Bakterien im Harne in grösserer Concentration finden, als im Blute, ein Umstand, auf den auch 
Wyssokowitsch (75) schon hingewiesen hat. In geringeren Mengen wird man einen mehr zufälligen Befund sehen dürfen. Wir müssen verlangen, dass bei einer vermehrten Diurese auch die Zahl der ausgeschiedenen Keime sich vermehrt, wenn die Ausscheidung der Bakterien physiologisoh, d. h. entsprechend der normalen Thätigkeit der Niere erfolgen soll.

Soweit die obigen Ausführungen die Secretionsorgane, Speichel- und Schleimdrüsen und Pankreas betreffen, sind sie durch die Untersuchungen von Biedl und Kraus $(3,4,5)$ unter Widerlegung der früheren Mittheilungen von Brunner $(8$ u. 9) u. A. experimentell als zu Recht bestehend erwiesen worden.

Die Milehdrüsen möchte ich, da hier die Verhältnisse in Folge der regelmässigen Anwesenheit der verschiedenartigsten Bakterien in den Milchgängen besonders verwickelt sind, von der Besprechung ausscheiden.

Was den Schweiss anlangt, so liegen zahlreiche Beobachtungen vor, die die Ausscheidung von Bakterien in demselben unter pathologischen Verhältnissen erweisen. Für eine Ausscheidung unter physiologischen Verbältnissen können die wenigen Versuche Brunner's (8), der im Schweisse der Katzenpfote einen Milzbrandbacillus fand und in demjenigen am Schweinsrüssel Prodigiosus, welche Keime vorher in die Blutbahn injicirt worden waren, nichts beweisen, um so weniger, als für den letzteren Versuch wenigstens dasselbe gilt, was gegen desselben Autors Versuche mit Speichel von Biedl und Kraus geltend gemacht wird. Diese glauben nämlich, dass nicht der Schweiss, bezw. Speichel die Bakterien enthalten hätte, sondern dass Blutungen aus kleinen Fissuren zu Täuschungen die Veranlassung gewesen wären. Brunner (9) selbst ist übrigens in einer späteren referirenden Arbeit der Ansicht, dass, bevor es zu einer Ausscheidung kommt, Gefässwände und Epithelien durchlässiger werden müssen, als es unter normalen Verhältnissen der Fall ist.

Eine Nachprüfung war mir wegen der Schwierigkeit, geeignete Thiere zu erlangen, nicht möglich. Als geeignet sind auch wohl nur Thiere zu bezeichnen, die, wie das Pferd, an der ganzen Hautoberfläche Schweissdrüsen besitzen, nicht solche, die, wie Sehwein und Katze, nur am Rüssel, bezw. der Pfote Schweiss secerniren. Bei der Unzuverlässigkeit unserer Methoden der Hautdesinfection sind Befunde im mensehlichen Scbweiss ganz ohne Bedeutung für unser Thema, ganz abgesehen davon, dass für gewöhnlich unser Blut keimfrei ist und eine Injection von leicht nachzuweisenden Mikroben sich von selbst verbietet.

Die Ausscheidung von Bakterien mit der Galle soll gleichfalls von der folgenden Besprechung ausgeschlossen bleiben, weil bei den verwickelten, verschiedenartigen und noch vielfach dunklen Functionen, die der Leber 
Ddrohgängigkeit von Darm und NIEREN fïr Bakterien. 531

obliegen; Sehlüsse aus beobachteten Erscheinungen nur einen sehr beschränkten Werth haben können.

Wesentlich einfacher liegen die Verhältnisse bei der Niere.

Um unnütze Wiederholungen zu vermeiden, verweise ich bezüglich der Litteratur auf die Arbeiten von Wyssokowitsch, Biedl und Kraus und v. Klecki.

Ich möchte hier nur kurz die Resultate anführen, die Wyssokowitsch bei seinen zahlreichen, an Kaninchen und Hunden mit den verschiedensten Bakterien angestellten Versuchen erhielt. Er kommt zu dem Seblusse, dass niemals eine physiologische.Ausseheidung von in die Blutbahn injicirten Bakterien stattfindet, sondern dass erst Veränderungen in den Nieren eingetreten sein müssen, wenn Bakterien im Harn erscheinen sollen. Diesen Untersuchungen ist von Orth (49), Biedl und Kraus u. A. der Vorwurf gemacht worden, dass die negativen Resultate zum grössten Theile auf der ungenügenden Methode der Harngewinnung aus der Blase post mortem beruhen. Spärlich vorhandene Keime könnten der Feststellung entgangen sein. Wie weit der Einwand berechtigt ist, ergiebt sich aus den gleich zu erwähnenden Versuchen von Biedl und Kraus; ich glaube, dass wenigstens ein Theil der negativen Befunde so erklärt werden muss.

In der Litteratur, die Biedl und Kraus anführen, finden sich die verschiedensten Ansichten über Art und Bedingungen einer Bakterienausscheidung durch die Nieren. Biedl und Kraus haben deshalb selbst in einer Reihe von neun Versuchen an Hunden, denen die Ureteren katheterisirt wurden, und an 17 Kaninchen, deren Harn continuirlich und nach dem Tode aus der Blase entnommen wurde, diese Verhältnisse von Neuem studirt. Aus den Protocollen ergiebt sich, dass in der That schon nach 5 Minuten der Staphylococcus pyogenes aureus aus dem Blute in den Harn übergehen kann, und dass die Methode des Urinauffangens aus den Ureteren wesentlich genauere Resultate giebt, als das Entnehmen des Harnes aus der Blase. Indessen waren die Thiere, bei denen der Harn continuirlich gewonnen wurde, chloroformirt, die anderen nicht. Ein nur nebenher erwähnter Fall bewies auch den Uebergang von Anilinblaukörnchen in den Harn kurze Zeit nach intravenöser Injection. In den Versuchen wurden die Hunde chloroformirt oder curarisirt, ebenso die Kaninchen, bei denen der Harn entweder aus den Treteren oder der Blase continuirlich aufgefangen wurde. Zur Injection dienten einige Cubikcentimeter einer mehrtägigen Bouilloncultur ron Staphylococcus pyogenes aureus; die Diurese wurde meist durch Kochsalz- oder Traubenzuckerinfusionen angeregt. 
In einer neuen Arbeit (5) über denselben Gegenstand, die auch noch die Ausscheidung von Bakterien durch andere drüsige Organe in den Bereich der Betrachtung zieht, referieren die Autoren ausführlich über Arbeiten von F. J. Cotton (18) und v. Klecki (53) und sehen in denselben eine Bestätigung ihrer eigenen Befunde. Sie kommen zu dem Schlusse, dass

„1. die normale unveränderte Gefässwand von im Blute kreisenden Mikroorganismen auf dem Wege der Diapedese passirt werden kann;

2. dass auch das intacte Gewebe der Passage kein Hinderniss entgegenstellt, dass aber

3. die Elimination der Mikroorganismen dennoch im Wesentlichen an den Bau und die specifische Leistung der betreffenden Drüsen geknüpft ist.

In diesem Sinne ist das Erscheinen der Mikroorganismen in den Drüsensecreten als wirkliche physiologische Ausscheidung zu betrachten.

Drüsige Organe, bei denen das Vorkommen einer solchen Ausscheidung nachgewiesen wurde, sind Niere und Leber."

Die Versuche ron Biedl und Kraus können aber für eine physiologische Secretion überhaupt nicht herangezogen werden, da sie unter gänzlich unphysiologischen Bedingungen stattfanden. Man bedenke nur, welche ungeheure Zumuthung an den Körper eine schnelle Vermehrung der Blutmenge auf das $1 \frac{1}{2}$ fache durch Traubenzuckerlösungen bedeutet und dass Chloroform und Aether die Nieren schwer zu schädigen im Stande sind. Selbst physiologische Kochsalzlösung ist durchaus nicht so sicher unschädlich für die Nieren. ${ }^{1}$

Etwas beweisen für die physiologische Ausscheidung ron Bakterien durch die Nieren könnten aber die Versuche v. Klecki's, ${ }^{2}$ in denen zum Theil ohne Anwendung von Nareoticis und Diureticis unter Controle des Blutdruckes und der Herzthätigkeit der Harn untersucht wurde. Er verwandte in seinen, nach einer ausserordentlich genauen Methode angestellten Versuchen Hunde, denen 0.1 bis 0.15 einer mehrtägigen Pyocyaneuscultur injicirt wurde. Auch bei verhältnissmässig so geringen Mengen von Bakterien und bei spontaner Harnabsonderung erschienen schon nach kurzer Zeit ( 3 bis 18 Minuten) die injicirten Mikrobien im Harn. Der Verfasser folgert daraus in Uebereinstimmung mit Biedl und Kraus, dass die normale Niere für Bakterien durchgängig sei.

Die Arbeit ron Cotton (18) war mir leider nicht im Original zugänglich, ich muss daher auf das Referat von Biedl und Kraus zurück-

Vgl. Sauer (64).

${ }^{2}$ Archiv fïr exper. Pathologie. 1897. Bd. XXXIX. Hft. 3. 
DURChgängtgketT VON DarMI UND NIEREN FÜr BakTERIEN. 533

greifen. Die sämmtlich an Kaninchen ausgeführten Versuche mit intravenöser Injection von Anthrax, Bacillus subtilis, Pneumococcus, Staphylokokken, Prodigiosus und Friedländer's Pneumobacillus ergaben sehr wechselnde Resultate bezüglich der Zeit und Menge der in Galle und Harn ausgeschiedenen Bakterien und der histologischen Befunde in den Organen. . Die Secrete wurden erst nach Tödtung der Thiere untersucht. Cotton legt Gewicht auf die Menge der ausgeschiedenen Bakterien für die Beurtheilung des Physiologischen an der Ausscheidung und kommt zu dem Ergebnisse, dass grössere Bakterienmengen im Harne scheinbar immer nur pathologiseh vorkommen; die Grenzen der angeblichen physiologischen Ausscheidung sind keineswegs festgestellt.

Ich selbst habe zur weiteren Klärung der Frage sieben Versuche an Hunden ausgeführt, deren Protocolle hier folgen:

\section{Versuchsprotocolle. ${ }^{1}$}

Versuch 1 .

Hund, $8200 \mathrm{gm}$. $0 \cdot 04$ Morfin subcutan. Während der Dauer der Operation Chloroformnarkose. Aufschwemmung stammt von 5 schrägen Agar-Oberflächen mit Vibrio Finkler-Prior, 21 Stunden bei $37^{\circ}$ gehalten. Zahl der eingeführten Bakterien $\mathrm{S}^{1 / 2}$ Billionen.

\begin{tabular}{|c|c|c|c|c|}
\hline Zeit & & R. Niere & $\mid$ L. Niere & Bemerkungen \\
\hline $12^{\mathrm{h}} 50-1^{\mathrm{h}}$ & $\begin{array}{l}\text { Infusion von } 60^{\mathrm{cm}} \text { physiol. } \\
\text { Kochsalzlösung in die linke } \\
\text { Vena jugularis }\end{array}$ & & & $\begin{array}{l}\text { Etwaige, ubrigens sehr } \\
\text { selten beobachtete Ver- } \\
\text { unreinigungen, die nie }\end{array}$ \\
\hline $1^{h}$ & $\begin{array}{c}\text { Einführen der Canïlen in } \\
\text { die Ureteren }\end{array}$ & & & $\begin{array}{l}\text { mehr als } 6 \text { Keime auf } \\
1 \text { Platte ausmachten, } \\
\text { sind hier, wie bei den }\end{array}$ \\
\hline $1^{\mathrm{b}} 10-1^{\mathrm{h}} 50$ & $\begin{array}{l}\text { Allmähl. Infusion der Bakt. } \\
\text { aufschwemmung in } 0.6 \text { proc. } \\
\text { Kochsalzlösung }\left(70^{\text {cem }}\right)\end{array}$ & $\begin{array}{l}\text { bis } 1^{\text {b }} 40 \\
\text { keine Urin- } \\
\text { secretion }\end{array}$ & $\mid \begin{array}{c}\text { keine } \\
\text { Urin- } \\
\text { secretion }\end{array}$ & $\begin{array}{c}\text { später. Versuchen nicht } \\
\text { besonders angeführt. } \\
\text { Urin klar. }\end{array}$ \\
\hline $1^{\text {b }} 40$ & Beginn der Urinsecretion & & & \\
\hline $1^{\mathrm{b}} 40-1^{\mathrm{h}} 45$ & 5 Tropfen klarer Urin & 0 & & \\
\hline $1^{\mathrm{h}} 45-1^{\mathrm{h}} 50$ & desgl. & 0 & & \\
\hline $1^{\mathrm{h}} 50-1^{\mathrm{h}} 5 \overline{5}$ & $1 / 2$ cems desgl. & 0 & & \\
\hline $1^{\mathrm{h}} 55-2^{\mathrm{h}}$ & desgl. & 0 & & \\
\hline $2^{\mathrm{h}}-2^{\mathrm{h}} 5$ & $11 / 9 \mathrm{ccm}$ Urin röthlich & $\begin{array}{c}\text { zahlr. Keime, } \\
\text { Gelatineplatte } \\
\text { verfliissigt }\end{array}$ & & \\
\hline $2^{\mathrm{h}} 5-2^{\mathrm{h}} 10$ & & 200 Colonieen & & \\
\hline $2^{\mathrm{h}} 10-2^{\mathrm{h}} 1 \mathrm{a}_{j}$ & Etwa 2 ccus Urin klar & 28 & & \\
\hline
\end{tabular}

1 Hr. Prof. Dr. Hürthle war so gütig, mir die Technik zu zeigen und mir die Mittel des physiologischen Institutes zur Verfügung zu stellen, wofür ich ihm anch an dieser Stelle meinen ergebensten Dank sage. 


\begin{tabular}{|c|c|c|c|c|}
\hline Zeit & & R. Niere & L. Niere & Bemerkungen \\
\hline $2^{\mathrm{h}} 15-2^{\mathrm{h}} 30$ & $\begin{array}{l}9 \mathrm{~cm} \text { Urin zur mikrosk. und } \\
\text { chem. Unters. aufgefangen }\end{array}$ & & & $\begin{array}{l}\text { Im Sediment keine } \\
\text { Bluthörperchen, } \\
\text { Eiweiss positiv. }\end{array}$ \\
\hline $2^{\mathrm{h}} 30-2^{\mathrm{h}} 35$ & $a^{\operatorname{com}}$ Urin, trüb & $\begin{array}{c}\text { Platte ganz } \\
\text { verflüssigt }\end{array}$ & & \\
\hline $\begin{array}{c}2^{\mathrm{h}} 35-2^{\mathrm{h}} 40 \\
2^{\mathrm{h}} 40\end{array}$ & $\begin{array}{c}\quad 2 \mathrm{ccm} \text { Urin } \\
\text { Tödten des Hundes. BInt- } \\
\text { entrahme aus dem Herzblut. } \\
\text { Aus demselben nach } 3 \text { Tagen } \\
\text { zahlreiche Colonieen Finkler- } \\
\text { Prior ausgewachsen. }\end{array}$ & desgl. & & \\
\hline
\end{tabular}

In den aus den Nieren angefertigten Schnitten colossale Hyperämie, besonders der Glomeruli, einzelne Hämorrhagieen. Im Gewebe der Niere keine Bakterien zu sehen bis auf ein einziges Präparat, in dem 2 Vibrionen in der Zwischensubstanz der Epithelien eines gewundenen Canälchens liegen. In den Epithelien der Tubuli contorti stellenweise reichliche gelbe Pigmentschollen.

$$
\text { Versuch } 2 .
$$

Hund, Gew. 5900 grm. 0.03 Morfin subcutan. Chloroformäther während der Operation. Sechs während 20 Stunden bei $22^{\circ}$ gehaltene schräge Agaroberflächen von Bac. prodigiosus mit $50^{\mathrm{ccm}}$ physiolog. Kochsalzlösung abgeschwemmt und zur Infusion verwandt. Dieselben enthalten 2.9 Billionen Keime. Hund lag auf erwärmtem Tische.

\begin{tabular}{|c|c|c|c|}
\hline Zeit & & R. Niere & Bemerkungen \\
\hline $\begin{array}{c}11^{\mathrm{b}} 55 \\
12^{\mathrm{h}} 5-12^{\mathrm{b}} 55\end{array}$ & $\begin{array}{c}\text { Einführen der Katheter. Bis zum } \\
\text { Beginn der Infusion } 1 \text { Tropfen, } \\
\text { l. keiri Urin. } \\
\text { Ganz allmähliche Infusion der } \\
\text { Aufschwemmung. }\end{array}$ & & $\begin{array}{c}\text { Von der linken Niere wurde } \\
\text { während der ganzen Dauer } \\
\text { des Versuches kein Urin } \\
\text { secernirt. }\end{array}$ \\
\hline $\begin{array}{c}12^{\mathrm{h}} 5-12^{\mathrm{h}} 10 \\
12^{\mathrm{h}} 10-12^{\mathrm{h}} 15 \\
12^{\mathrm{h}} 15-12^{\mathrm{h}} 20 \\
12^{\mathrm{h}} 20-12^{\mathrm{h}} 25 \\
12^{\mathrm{h}} 25-12^{\mathrm{h}} 30 \\
\text { u. s. w. }\end{array}$ & $\begin{array}{l}\text { In } 5 \text { Min. immer nur je } 1 \text { Tropf. } \\
\text { klaren Urins erhalten. }\end{array}$ & 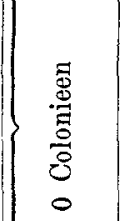 & \\
\hline $\begin{array}{l}1^{\mathrm{h}} 5-1^{\mathrm{b}} 30 \\
\text { Letzter Urin } \\
1^{\mathrm{b}} 55-2^{\mathrm{b}} 5\end{array}$ & $\begin{array}{l}\text { Infusion von } 200^{\text {cem }} 5 \text { procentig. } \\
\text { Traubenzuckerlösung. } \\
\text { Ohne Erfolg für die Urinsecretion. }\end{array}$ & & $\begin{array}{l}\text { Nach } 2 \text { Stunden Versuch } \\
\text { beendet. Im r. Katheter } \\
\text { 5Tropfen stark blutig. Urins, } \\
\text { der zablr. Prodigiosuskeime } \\
\text { enthält. Im l. Katheter } 2 \\
\text { Tropfen, enthaltend } 16 \text { Keime } \\
\text { Prodigiosus. Blat enthält } \\
\text { sehr reichlich Prodigiosus. }\end{array}$ \\
\hline
\end{tabular}

Die von den Nieren angefertigten Schnitte bieten dasselbe Bild wie in Vers. 1. Nur sind in keinem der Schnitte im Gewebe Bakterien gefunden worden. 


\section{Versuch 3 .}

Hund, Gew. $7300 \mathrm{grm}$, auf den ungeheizten Operationstisch gelagert. Zur Infusion wird eine Aufschwemmung von 3 bei $22^{\circ}$ während 21 Stunden gehaltener Agarculturen von Coccus aquatilis in $50 \mathrm{ccm}$ Kochsalzlösung benutzt. Dieselbe enthält 780 Milliarden Keime. 0.04 Morfin und Chloroformäther während der Operation.

\begin{tabular}{|c|c|c|c|c|}
\hline Zeit & & R. Niere & L. Niere & Bemerkungen \\
\hline $11^{\mathrm{h}}$ & $\begin{array}{l}\text { Einführen der Katheter } \\
\text { in die Ureteren. }\end{array}$ & & & $\begin{array}{c}\text { Reichliche Secretion } \\
\text { klaren Urins }\end{array}$ \\
\hline $11^{\mathrm{h}} 5-11^{\mathrm{h}} 25$ & $\begin{array}{c}\text { Infusion von } 300^{\mathrm{cm}} \text { Koch- } \\
\text { salzlösung. }\end{array}$ & & & \\
\hline $11^{\mathrm{h}} 30-11^{\mathrm{h}} 50$ & Infus. der Aufschwemmung & & & \\
\hline $11^{\mathrm{h}} 30-11^{\mathrm{h}} 35$ & R. u. L. ${ }^{3} / 4{ }^{\mathrm{com}}$ klarer Urin. & 0 Col. & $0 \mathrm{Col}$ & \\
\hline $11^{\mathrm{h}} 35-11^{\mathrm{b}} 40$ & & 0. & 0, & \\
\hline $11^{\mathrm{h}} 40-11^{\mathrm{b}} 45$ & , & 0, & 0 , & $\begin{array}{l}\text { Harnsecretion nimmt } \\
\text { allmählich ab. }\end{array}$ \\
\hline $11^{\mathrm{b}} 45-11^{\mathrm{h}} 50$ & & 0, & 0 & \\
\hline $11^{\mathrm{h}} 50-12^{\mathrm{h}} 00$ & & 0, & 0, & Hund friert. \\
\hline $12^{\mathrm{h}} 00-12^{\mathrm{h}} 10$ & & 0 , & $0 \quad$, & \\
\hline $12^{\mathrm{h}} 10-12^{\mathrm{b}} 20$ & R. u. L. nur 2 Tr. in 5 Min. & 0 & 0, & \\
\hline $12^{\mathrm{h}} 20-12^{\mathrm{b}} 30$ & & 0, & 0, & \\
\hline $12^{\mathrm{h}} 30-12^{\mathrm{h}} 40$ & & 0 , & 0, & \\
\hline $12^{\mathrm{h}} 40-12^{\mathrm{h}} 50$ & R. u. L. 6 bez. 5 Tr. in 5 Min & $0 \quad$, & 0, & \\
\hline $12^{h} 50-1^{h}$ & $\begin{array}{l}\text { Urinsecretion wieder } \\
\text { reichlicher, zunehmend. }\end{array}$ & $6 "$ & & \\
\hline $1^{h} 00-1^{h} 10$ & P. $1 \frac{1}{2}$, L. $1^{3} / 4^{\cos }$ in $10 \mathrm{Min}$. & & 27, & \\
\hline $1^{b} 10-1^{b} 20$ & & 22, & 46, & \\
\hline $1^{\mathrm{b}} 20-1^{\mathrm{h}} 30$ & & 34, & $44 \quad$, & \\
\hline $1^{h} 30-2^{h} 30$ & $\begin{array}{l}\text { Harn zur mikroskop. und } \\
\text { chem. Untersuchung von } \\
\text { jeder Seite besouders auf- } \\
\text { gefangen. }\end{array}$ & $\begin{array}{c}\text { röthlich } \\
\text { gefärbt. } \\
\text { Urin }\end{array}$ & $\begin{array}{l}\text { klar- } \\
\text { gelber } \\
\text { Urin }\end{array}$ & $\begin{array}{l}\text { Urin von beiden Seiten } \\
\text { enthält zahlreiche rothe, } \\
\text { spärliche, weisse Blut- } \\
\text { körperchen, daneben eine } \\
\text { grosse Menge stark licht- } \\
\text { brechend.Kügelchen (kein } \\
\text { Fett). Eiweiss positiv, } \\
\text { reichlich }\end{array}$ \\
\hline
\end{tabular}

Im mikroskopischen Bilde an einzelnen Stellen der Nierenrinde colossale Massen von Kokken regellos durch das Gewebe vertheilt. Sehr starke Hyperämie, besonders auffällig in den Glomerulis, und zahlreiche Blutungen im Gewebe. Im Epithel der gewundenen Harncanälchen herdweise dieselben gelben Pigmentsehollen wie bei Vers. 1 und 2. 


\section{Versuch 4.}

Hund, Gew. 11000 grm. Erhält 0.06 Morfin subcutan, während der Operation Chloroformäther. Am Abend vor der Operation mit Salzfleisch gefüttert, reichlich getränkt. Carotis zur Blutentnahme frei präparirt. Injection von $1^{\mathrm{ccm}}$ unfiltrirter Aufschwemmung einer alten Cultur eines rothen Farbstoff bildenden, sehr langsam wachsenden Coccus aus der Luft.

Gahalt 80000000 Keime.

\begin{tabular}{|c|c|c|c|c|c|c|}
\hline Zeit & - & \multicolumn{2}{|c|}{ R. Niere } & \multicolumn{2}{|c|}{ L. Niere } & Bemerkungen \\
\hline $10^{\mathrm{h}} 45-11^{\mathrm{h}}$ & $\begin{array}{l}\text { Reichl. Urinsecretion, links } \\
\text { reichlicher als rechts. }\end{array}$ & & Col. & & Col. & $\begin{array}{l}\text { Urin makroskop. während } \\
\text { der ganzen Dauer des }\end{array}$ \\
\hline $11^{\mathrm{h}}$ & $\begin{array}{l}\text { Injection der Aufschwem- } \\
\text { mung in die l. Jugularis. }\end{array}$ & 0 & $"$ & 0 & $"$ & Versuches klar gelb. \\
\hline $11^{\mathrm{h}} 00-11^{\mathrm{h}} 5$ & R. $1 / 2, \quad$ L. $3 / 4 \mathrm{ccm}^{\mathrm{cm}}$ & 0 & , & 0 & & \\
\hline $11^{\mathrm{h}} 5-11^{\mathrm{h}} 10$ & & 0 & $\therefore$ & 0 & , & \\
\hline $11^{\mathrm{b}} 10-11^{\mathrm{h}} 15$ & & 0 & , & 0 & , & $\begin{array}{l}\text { Erste Blutentnahme. In } \\
1^{\mathrm{cm}} \text { defibr. Blutes } 100 \mathrm{~K} .\end{array}$ \\
\hline $11^{\mathrm{k}} 15-11^{\mathrm{h}} 20$ & R. a. L. $1 / 3 \mathrm{sem}^{\mathrm{cem}} 5 \mathrm{Min}$. & 5 & , & 0 &, & \\
\hline $11^{\mathrm{h}} 20-11^{\mathrm{h}} 40$ & R. 2, L. $1^{1 / 2}{ }^{\mathrm{ccm}}$ in $20 \mathrm{Min}$. & 25 & , & 0 & " & \\
\hline $11^{\mathrm{h}} 40-11^{\mathrm{h}} 45$ & & 0 & , & 0 & , & \\
\hline $11^{\mathrm{h}} 45-11^{\mathrm{h}} 50$ & & 0 &, & 0 & ” & \\
\hline $11^{\mathrm{h}} 50-12^{\mathrm{h}} 00$ & Pu. 1, L. $1 / 3 \mathrm{cem}$ & 0 & , & 0 & , & $\begin{array}{l}\text { Zweite Blutentnahme. } \\
77 \text { Keime in Cubikcent. }\end{array}$ \\
\hline $12^{\mathrm{h}} 00-12^{\mathrm{h}} 10$ & & 0 & , & 0 & ", & \\
\hline $12^{\mathrm{h}} 10-12^{\mathrm{h}} 20$ & & 0 & , & 0 & , & \\
\hline $12^{\mathrm{h}} 20-12^{\mathrm{h}} 30$ & R. u. L. nur je $1 \operatorname{Tr}$ Urin. & 0 & " & 0 & , & $\begin{array}{l}\text { Dritte Blutentnahme } 39 \mathrm{~K} \text {. } \\
\text { im Cubikcentimeter. Der } \\
\text { nach Beendignng des Ver- } \\
\text { suches aufgefangene Urin } \\
\text { wurde durch ein Versehen } \\
\text { fortgegossen. }\end{array}$ \\
\hline
\end{tabular}

In den mikroskopischen Präparaten findet sich wieder Hyperämie und auch einzelne aber seltene Hämorrhagieen. Im Gewebe nirgends Keime zu sehen.

${ }^{1}$ Das entnommene Blut wurde defibrinirt und sofort zur Aussaat gebracht. In den folgenden Versuchen wurden, nm jede baktericide Wirkung auszuschliessen, 10 ccm Blut in $5 \mathrm{~cm} 25$ proc. $\mathrm{Mg}$-Sulfatlösung aufgefangen ( $\mathrm{Nissen}$ ), dann auch sogleich in die Nährböden gebracht.

Anm. Die alte Cultur wurde benutzt, da die frisch angelegten Culturen von Bacillus liquefaciens fluorescens nicht angegangen waren. 
Versuch 5.

Hund, Gew. $14500 \mathrm{gm}$, wie bei Vers. 4 vorbereitet, bekommt 0.07 Morfin und während der Operation Chloroformäther. Injicirt wird in die linke Vena jugularis $1 / 2$ ecm einer filtrirten Aufschwemmung von einer 19 Stunden bei $22^{0}$ gewachsenen Bac. fluor. liquef.-Agareultur. Dieselbe enthält $10000000 \mathrm{~K}$.

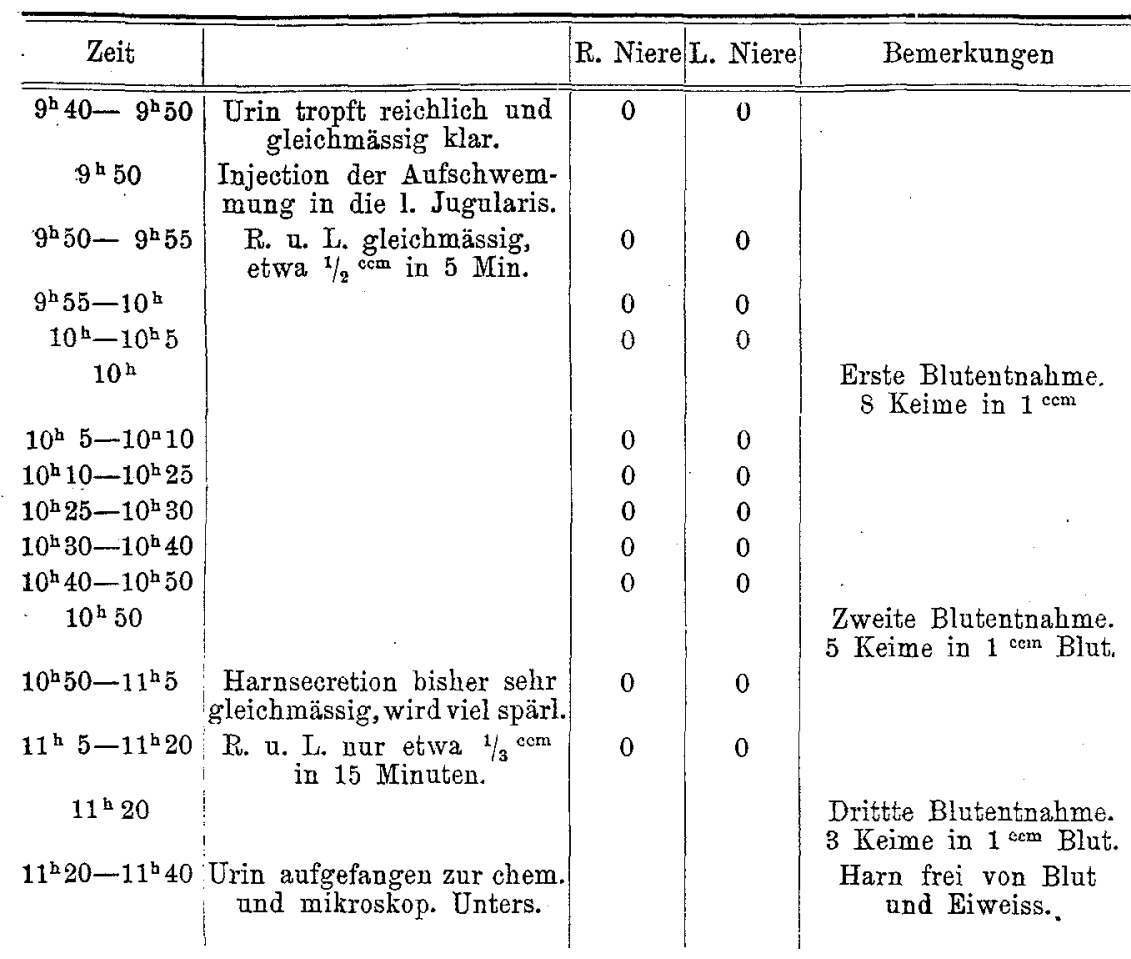

Mikroskop. Präparate: In beiden Nieren ist die Rinde hyperämisch, man sieht erweiterte Gefässe, trotzdem der Hund durch Entbluten getödtet wurde. Hämorrhagieen und Bakterien im Gewebe nirgends zu finden.

\section{Versuch 6.}

Hund, Gew. 8950 grm. 0.04 Morfin subcutan. Zur Operation Narcose mit Chloroformäther. Am Abend vorher mit Salzfleisch gefüttert und reichlich mit Milchwasser getränkt. Drei bei $22^{\circ}$ während 19 Stunden gehaltene Culturen des Bac. fluor. liquef. auf schrägem Agar werden mit physiolog. Kochsalzlösung abgeschwemmt und filtrirt. $3^{\mathrm{ccm}}$ injicirt. Dieselben enthielten - geschätzt - 60 bis 80 Millionen Keime. (Die Zählplatten waren durch ein Versehen vorzeitig entfernt worden.) Urinsecretion, im Anfang schwach, nimmt bald nach der Infusion allmählich zu, auf beiden Seiten ziemlich gleichmässig. 


\begin{tabular}{|c|c|c|c|c|}
\hline Zeit & & R. Niere & L. Niere & Bemerkungen \\
\hline $9^{\mathrm{h}} 20-9^{\mathrm{h}} 30$ & $\begin{array}{c}\text { Secretion } 1 / 4 \mathrm{ccm} \text { in } 10 \mathrm{Min} . \\
\text { beiderseits. }\end{array}$ & 0 & 0 & Urin klar. \\
\hline $9^{h} 30-9^{h} 40$ & $\begin{array}{c}\text { Langsame Injection der } 3^{\mathrm{cm}} \\
\text { in die 1. Vena jugularis. }\end{array}$ & & & \\
\hline $9^{2} 30-9^{h} 35$ & & 0 & 0 & \\
\hline $9^{h} 35-9^{h} 40$ & & 0 & 0 & \\
\hline $9^{h} 40-9^{h} 45$ & & 0 & 0 & \\
\hline $9^{h} 45-9^{h} 50$ & $\begin{array}{l}\text { R. u. L. } 1 \text { cem klarer Urin } \\
\text { in } 5 \text { Minuten. }\end{array}$ & 0 & 0 & $\begin{array}{l}\text { Erste Blutentnahme. } \\
\text { In } 1 \mathrm{ccm} 617 \text { Keime. }\end{array}$ \\
\hline $9^{\mathrm{h}} 50-10^{\mathrm{h}} 15$ & & 0 & 0 & \\
\hline $10^{\mathrm{h}} 15-10^{\mathrm{h}} 30$ & $\begin{array}{c}\text { Beiderseits } 3 \text { em in } 15 \mathrm{Min} . \\
\text { Urin klar. }\end{array}$ & 0 & 0 & $\begin{array}{l}\text { Zweite Blutentnahme. } \\
34 \text { Keime in } 1 \mathrm{~cm} \text {. }\end{array}$ \\
\hline $10^{\mathrm{h}} 30-10^{\mathrm{h}} 45$ & & 0 & 0 & \\
\hline $10^{\mathrm{h}} 45-11^{\mathrm{h}}$ & $\begin{array}{c}\text { R. } 1 \mathrm{~cm} . \text { L. } 2 \mathrm{cem} \text { klarer } \\
\text { Harn in } 15 \text { Min. }\end{array}$ & 0 & 0 & $\begin{array}{l}\text { Dritte Blutentnahme. } \\
7 \text { Keime in } 1 \mathrm{ecm} .\end{array}$ \\
\hline $11^{\mathrm{h}} 00-11^{\mathrm{h}} 30$ & $\begin{array}{l}\text { Urin gesammelt, makroskop. } \\
\text { völlig klar. }\end{array}$ & & & $\begin{array}{l}\text { Zahlreiche rothe Blat- } \\
\text { körperchen im Harn. } \\
\text { Eiweiss stark positiv. }\end{array}$ \\
\hline
\end{tabular}

Hund durch Entbluten getödtet. In den Nierenrinden makroskopisch zahlreiche strich- und punktförmige Blutansammlungen erkennbar.

Mikroskopisch zahlreiche Blutungen, die sich in den Gewebsspalten einen Weg gebahnt haben, stellenweise auch grössere Ansammlungen von Blut. Gefässe stark zusammengefallen, besonders in den Glomeruli, die die Kapsel nur noch theilweise ausfüllen. Auch innerhalb derselben kleine Blutungen. Nirgends im Gewebe Bacillen zu finden.

\section{Versuch 7 .}

Hund, Gew. $8970^{\text {arm. }}$. Vorbereitung wie bei Vers. 4-6. 0.05 Morfin. Zur Operation Chloroformäther. Von einer filtrirten Aufschwemmung von vier Agaroberflächen mit B. fluor. liquef., die 20 Stunden bei $22^{\circ}$ gewachsen waren, werden $3^{\mathrm{ccm}}$ injicirt. Dieselben enthalten 110000000 Keime. Urinsecretion, von Anfang an beiderseits reichlich, steigert sich sofort nach der Injection colossal.

\begin{tabular}{|c|c|c|c|c|c|c|c|}
\hline Zeit & \multicolumn{2}{|c|}{ R. Niere } & Wachsth. & \multicolumn{2}{|c|}{ L. Niere } & Wachsth. & Bemerknngen \\
\hline $10^{\mathrm{h}} 15-10^{\mathrm{h}} 25$ & \multicolumn{2}{|c|}{$\begin{array}{c}1 \text { com klarer } \\
\text { Urin }\end{array}$} & 0 & \multicolumn{4}{|c|}{$\begin{array}{c}1 \mathrm{~cm} \text { klarer } 1 \text { Schimmel } \\
\text { Urin }\end{array}$} \\
\hline $10^{\mathrm{h}} 25-10^{\mathrm{h}} 32$ & \multicolumn{7}{|c|}{ Allmähliche Injection von $3 \mathrm{ccm}$ Aufsehwemmung in die 1. Vena jugul } \\
\hline $10^{\mathrm{h}} 25-10^{\mathrm{h}} 30$ & \multicolumn{2}{|l|}{$1 \mathrm{com}$} & 0 & \multicolumn{2}{|l|}{$1 \mathrm{cem}$} & 0 & \\
\hline $10^{\mathrm{h}} 30-10^{\mathrm{h}} 35$ & $2_{1 / 2}^{1 / 2}$, & & 0 & & & 0 & \\
\hline $10^{\text {t }} 35-10^{\text {h }} 40$ & , & $\stackrel{\infty}{\pi}$ & 0 & 3 & $\stackrel{n}{=}$ & 0 & \\
\hline $10^{\mathrm{h}} 40-10^{\mathrm{h}} 45$ & 3 & 象 & 0 & $3 y$ & $\overline{7}$ & 0 & \\
\hline $10^{\mathrm{h}} 45-10^{\mathrm{h}} 50$ & , & $\approx$ & 0 & 3 & & 0 & $\begin{array}{l}\text { Erste Blutentnahme. } \\
120 \text { Keime in } 1 \mathrm{~cm} \text {. }\end{array}$ \\
\hline $10^{\mathrm{h}} 50-11^{\mathrm{h}} \check{5}$ & 9 & $\frac{\pi}{2}$ & 0 & 10 & 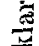 & 0 & \\
\hline $11^{\mathrm{h}} 5-11^{\mathrm{b}} 15$ & , & & 0 & 4, & & 0 & \\
\hline $11^{\mathrm{h}} 15-11^{\mathrm{h}} 25$ & , & & 0 & $2^{1 / 2}$, & & 0 & \\
\hline
\end{tabular}


Durchä̈ngtgkeit von Darm und Nigren für Bakterien. 539

\begin{tabular}{|c|c|c|c|c|c|}
\hline Zeit & R. Niere & Wachsth. & L. Niere & Wachsth. & Bemerkungen \\
\hline $\begin{array}{l}11^{\mathrm{h}} 25-11^{\mathrm{h}} 40 \\
11^{\mathrm{h}} 40-11^{\mathrm{b}} 55\end{array}$ & $\begin{array}{l}4 \text { ecm } \\
3, \text { Klar. } \\
3, \text { Urin }\end{array}$ & $\begin{array}{l}0 \\
0\end{array}$ & \begin{tabular}{l|c}
3 & $\mathrm{com}$ \\
klar. \\
3 Harns
\end{tabular} & $\begin{array}{l}0 \\
0\end{array}$ & $\begin{array}{l}\text { Zweite Blutentrahme. } \\
6 \text { Keime in } 1 \mathrm{com} \text {. }\end{array}$ \\
\hline $11^{\mathrm{h}} 55-12^{\mathrm{h}} 25$ & Urin zur $n$ & likroskop. & chem. Unt & tersuchung. & $\begin{array}{l}\text { Dritte Blutentnahme. } \\
\text { 1. Platte 0 Keime in } 1 \text { com } \\
2 . " 29 \quad ", " \\
\text { Urin enthält reichl. rothe } \\
\text { Blutkörp., kein Eiweiss. } \\
\text { Aussehen völlig klar. }\end{array}$ \\
\hline
\end{tabular}

Makroskopisch bieten die Nieren dasselbe Bild wie bei Versuch 6; mikroskopisch ebenfalls.

Die Hunde wurden zu den Versuchen in Morphium-Chloroformnarkose laparotomirt, nach Aufsuchen der Ureteren kurz vor dem Eintritt in's kleine Becken wurden in dieselben sterilisirte Metallkatheter bis hinauf in's Nierenbecken eingefübrt, darauf die Bauchhöhle provisorisch wieder vernäht. Aufsuchen der Jugularis und Einbinden einer Canüle in dieselbe bei den ersten drei Versuchen. In den letzten vier Versuchen wurde die Infection mit einer Pravaz-Spritze in's Lumen der Vene hinein gemacht. Bei diesen vier Versuchen wurde auch die Carotis frei präparirt, um aus derselben von Zeit zu Zeit Blut entnehmen zu können. ${ }^{\text {? }}$

Erst nach Beendigung aller dieser Operationen und nach Aussetzen der Chloroform-Aethernarkose begann die Injection in die Jugularis. Der vor derselben secernirte Harn wurde im Ganzen aufgefangen und untersucht. Der nachher abtröpfelnde Harn wurde während der Dauer des Versuches vollständig in Gelatineröhrchen aufgefangen, die zuerst alle 5 Minuten, später seltener gewechselt wurden. Der nach Beendigung des Versuches entleerte Harn diente zur Untersuchung auf Blut und Eiweiss. In den ersten drei Versuchen wurden übertrieben grosse Mengen nicht pathogener Bakterien verwandt, in der Hoffnung, dadurch die Wege deutlich zu machen, auf denen die Bakterien die Niere verlassen, auch wenn

1 Die Carotis wird zu diesem Zweeke auf etwa $5^{\mathrm{em}}$ frei präparirt, am proximalen und distalen Ende angeschlungen; erstere Schlinge dient nur zur Sicherung. Etwa $1^{\text {sm }}$ oberhalb der distalen Fadenschlinge wird ein Faden tangential zu dem Gefässe durch die Adventitia genäht, geknotet und mit einer Schieberpincette gefasst. In der Nähe der proximalen Schlinge wird eine nicht zu stramme Klemmpincette angelegt, darauf die distale Schlinge fest geknotet und die Carotis zwischen Knoten und Schieberpincette durchschnitten. Unter Führung der letzteren kann man dann nach Oeffnung der Klemme jeder Zeit beliebige Mengen Blut in Gefässen steril auffangen. 
keine Intoxication des Thieres erfolgt. Die injicirten Flüssigkeitsmengen wurden so langsam und unter so geringem Druck eingeführt (höchstens $40 \mathrm{~cm}$ Wasserhöhe), dass eine directe Schädigung dadurch ausgeschlossen war. Dass die Urinsecretion bei den ersten beiden Hunden so gering war, liegt wahrscheinlich daran, dass dieselben auf einem geheizten Tische lagen, was bei den späteren Versuchen vermieden wurde. Ich habe nichtpathogene Bakterien gewählt, um im Falle eines positiren Resultates den Einwand ausschliessen zu können, dass die Bakterien durch ihre giftigen Stoffwechselproducte eine Schädigung der Zellen erzeugt hätten. Ich ging dabei von folgender Erwägung aus. Wenn die pathogenen Bakterien im Stande sind, durch ihre Stoffwechselproducte oder unter Zerfall ihrer Leibessubstanz die Zellen des gesammten Körpers zu vergiften, so müssen dazu auch einzelne Bakterien, die sich an die Zellen direct anlegen, diesen gegenüber im Stande sein. Eine solche innige Berührung muss aber beim Durchtritt durch die Gefässwände und die Drüsenepithelien statthaben. Gerade die der Durchtrittsstelle benachbarten Zellen befinden sich also, falls es sich um pathogene oder giftige Bakterien handelt, während der Anlagerung und des Durchtrittes unter Giftwirkung. Dass zur Herworbringung derselben eine längere Zeit nothwendig wäre, ist nicht nöthig anzunehmen; es macht durchaus keine Schwierigkeiten, sich vorzustellen, dass zum Mindesten eine Lähmung sich fast momentan einstellen kann. Sind uns doch Gifte bekannt, die wie Blausïure oder Arsenwasserstoff den fast augenblicklichen Tod eines ganzen Individuums herbeiführen können. Wenn man ein gesundes junges Thier mit Aether oder Chloroform rergiftet, so findet sich schon nach wenigen Minuten eine schwere totale fettige Degeneration des Herzmuskels. Dass thatsïchlich bei länger bestehender Infection bleibende degenerative Veränderungen der Gefässe und Nierenepithelien entstehen können und unter solchen Verbältnissen die Passage für Mikroorganismen ermöglicht wird, ist, wie ja auch Biedl und Kraus zugeben, allgemein anerkannt. Dass es sehr schnell zu Blutungen kommen kann, zeigen meine Präparate; feinere mikroskopische Veränderungen der Gefässe sind schon nach 2 Stunden sichtbar gemacht worden (Biedl und Kraus (3), S. 22).

Man wird wohl nicht fehl gehen, wenn man den Beginn solcher Veränderungen in die erste Zeit nach eingetretener Infection verlegt, wobei man sich nur klar machen muss, dass dieselben zuerst leichterer, etwa „moleculärer" Art und bei Aufhören der Schädlichkeit der restitutio ad integrum fähig sein können. Dass diese Annahme nach Biedl und Kraus unberviesen und überflüssig ist, beweist nichts gegen ihre Mröglichkeit. $\mathrm{Ob}$ sich derartige Veränderungen in den Zellen, die ja auch vorïbergehender Natur sein kömen, jemals werden histologisch feststellen lassen, ist sehr 
fraglich, indessen stehen hier noch Untersuchungen mit wirklich genauen Methoden aus. ${ }^{1}$ Man wird von derartigen Untersuchungen allerdings nicht zu viel erwarten dürfen, da nicht alle Zellen Veränderungen zeigen werden, sondern nur die einer Durchtrittsstelle benachbarten. Diese zu Gesicht zu bekommen, wird sich nur durch Anfertigung grosser Schnittreihen erreichen lassen. Ich habe daher meine ursprüngliche Absicht, den feinsten Structurveränderungen der Zellen nachzuforschen, um so leichter aufgegeben, als sich in meisten Präparaten handgreifliche Veränderungen fanden.

Nach dem Gesagten muss ich die Folgerung für unzulässig halten, dass eine schädigende Wirkung auf die Gefässe und Epithelien durch Bakteriengifte nicht stattgefunden haben könne, wenn $z$ wischen Injection und Erscheinen von Bakterien im Harn nur ein nach wenigen Minuten zu bemessender Zeitabschnitt liegt.

Hierzu kommt noch etwas Weiteres. Die ,geringen" Mengen vou Bakterien, welche v. Klecki in einem Theil seiner Versuche verwandte, entsprechen durchaus noch nicht dem, was ausserhalb des Experiments vorkommt. Zunächst befinden sich Biedl und Kraus im Irrthum mit der Annahme, dass v. Klecki $0.15^{\mathrm{ccm}}$ u. s. w. der hergestellten Aufschwemmung zur Injection benutat habe. Es handelt sich um den entsprechenden Theil der auf der Agaroberfläche gewachsenen Bakterien, und v. Klecki giebt selbst an, dass er mehrere Cubikcentimeter der hergestellten Aufschwemmung injicirt habe und zugleich von der Verdünnang eine Verminderung der toxischen Wirkung erhoffte. Sein Zweck, dadurch die Verhältnisse bei spontanen Erkrankungen nachzuahmen, ist indessen nicht erreicht. Erstens werden immerhin bei seinem Verfahren noch eine grosse Menge von Toxinen in die Blutbahn mit eingeführt, um so mehr, als er meist mehrtägige Culturen benutzte. Ferner ist auch so noch die Zahl der injicirten Bakterien erheblich grösser, als sie bei septikämischen Erkrankungen zu sein pflegt. Nach den Zählungen v. Klecki's fanden sich im Blute nach der Injection oft mehrere Hundert Keime pro Cubikcentimeter, ${ }^{2}$ während in den positiven Fällen von Kühnau (39) die Zahl niemals 3 bis 4 Keime in 10 bis $20^{\mathrm{cm}}$ Blut überstieg, gewiss noch ein beträchtlicher Unterschied. Ich habe, da die Zahl der Bakterien

\footnotetext{
${ }^{1}$ Eine sehr genaue Methode der histologischen Untersuchung ist von Sa uer (64) angegeben worden, und es ist durchaus nicht unwahrscheinlich, dass sich mit derartigen Untersuchungen Veränderungen schon zu einer Zeit sichtbar machen lassen werden, wo wir es bisher nicht vermutheten. Auch auf anderen Gebieten (z. B. durch die Nissl'sche Färbung der Ganglienzellen) sind auf diese Weise erhebliche Fortschritte gemacht worden.

${ }^{2}$ Irn Versuch 2652 Minuten nach Injection von 0.04 einer 3 tägigen Cultur noch 378 Keime pro Cabikcentimeter, in Versuch 281 Stunde 8 Min. nach Injection von 0.05 einer 2 tägigen Cultur in $1 \mathrm{cms} 46$ Keime u. s. w.
} 
E. OPITZ:

nach der Zahl und dem Alter der verwandten Agarculturen nur sehr ungenau zu bestimmen ist, die injicirten Bakterien vermittelst Verdünnung und Plattenzählung direct gezählt, ferner zur Vermeidung der Einführung von Toxinen nicht über 21 Stunden alte Culturen verwandt. Nach den Zählungen ergiebt sich, dass nach 20 Stunden Wachsthum bei $37^{\circ}$ auf einer Agaroberfläche etwa 500000000000 Prodigiosuskeime vorhanden waren; beim Vibrio Finkler-Prior noch mehr, bei Coccus aquatilis etwas weniger. Der hundertste Theil einer solchen Cultur enthält also immer noch 5000000000 Keime. Nehmen wir für den Pyocyaneus und die älteren Culturen auch viel geringere Zahlen an, so bleiben immer noch Bakterienmengen übrig, wie sie unter natürlichen Verbältnissen wohl niemals in der Circulation vorhanden sein werden, so dass also auch von v. Klecki's Versuchen nicht angenommen werden kann, dass sie unter Bedingungen ähnlich den in der Natur vorkommenden stattgefunden hätten.

Ein anderer Punkt ist auch noch von Wichtigkeit; in unfiltrirten Abschwemmungen, wie sie v. Klecki anwandte, finden sich immer grüssere Bröckel, die, wenn auch nicht mit blossem Auge sichtbar, doch im Stande sein können, Capillargefässe zu verstopfen. Bleiben die grösseren bei Injection in eine Vene auch in den Lungen stecken, so können immer noch durch die dort weiteren Capillaren Partikel hindurchgehen, die in den Nieren Alterationen des Kreislaufes herbeizuführen im Stande sind. Ich habe dies zu vermeiden gesucht, indem ich die Abschwemmungen durch sterile Filter gehen liess.

Durch die in der Litteratur vorliegenden Versuche ist nur Folgendes einwandsfrei nachgewiesen worden: dass nach oft schon sehr kurzer Zeit (im Minimum 3 Ninuten) in die Blutbahn gebrachte Mikroorganismen im Harn wieder erschienen, auch ohne künstliche Anregung der Harnsecretion und ohne dass rothe Blutkörperchen oder Eiweiss im Harn sich zeigten.

Damit ist aber meines Erachtens nach den obigen Ausführungen nichts dafür bewiesen, dass es sich um eine physiologische Ausscheidung handelt.

Die Kürze der Zeit und die Anwendung geringer Bakterienmengen - durch $\nabla$. Klecki beweist, wie erörtert, durchaus noch nichts gegen die Möglichkeit einer Schädigung der betheiligten Zellen durch die Bakteriengifte. Ferner liegt es im Wesen einer "physiologischen" Function, dass dieselbe innerhalb gewisser Grenzen unter gleicher Veranlassung in gleicher Weise eintritt. Wenn wir uns darauf die Versuche v. Klecki's ansehen, so finden wir diese Bedingung nicht erfüllt. Einmal setzt die Ausscheidung der Bakterien niemals so prompt ein, wie wir dies fordern müssten, und ferner hört sie auf, wenn noch Bakterien im Blute kreisen 
in einer Zahl, wie sie selbst bei schwersten Infectionen auf natürlichem Wege zum Mindesten sehr selten vorkommt. So z. B. in Versuch 17, wo eine Ausscheidung 22 Minuten, nachdem 104 Keime im Cubikcentimeter Blut gezählt waren, zum letzten Male eintrat. 1 Stunde später waren noch 10 Keime in 1 cem Blut enthalten. Bei Versuch 28 kam es überhaupt zu keiner Ausscheidung, obwohl in $1 \mathrm{~cm}$ Blut nach 1 Stunde 8 Minuten 44 Keime kreisten. In einem Theile der Versuche unterblieb überhaupt jede Ausscheidung in der Beobachtungszeit.

Biedl und Kraus, sowie v. Klecki weisen übrigens selbst zum Ueberfluss darauf ausdrücklich hin, dass ceteris paribus eine Ausscheidung (von Bakterien) durch die Nieren erfolgen kann, aber nicht muss, bestreiten also selbst das „Physiologische" an diesem Vorgange. Oder wir müssten dann in den Fällen, wo eine Ausscheidung nicht statthat, nach Ursachen für ein Ausbleiben dieses physiologischen Vorganges suchen, d. h. annehmen, dass gerade in den Fällen, wo keine Bakterien im Harn erscheinen, pathologische Verbältnisse vorliegen, und dafür haben wir nicht den geringsten Anhalt. Biedl und Kraus, sowie v. Klecki selbst bleiben uns eine Errklärung für die Ursache, weshalb ein Mal eine Ausscheidung statthat, ein anderes Mal nicht, schuldig.

Ein weiterer Grund gegen die Annahme einer physiologisehen Ausscheidung liegt in den histologischen Befunden. Wir finden die Bakterien nicht in den Drüsenepithelien, sondern der Austritt rollzieht sich in den Glomerulis. ${ }^{2}$ Wäre von einer, den normalen Verhältnissen entsprechenden Ausscheidung der Bakterien aus dem Blute die Rede, so müsste, nach Analogie der in's Blut gespritzten Milch-Fetttröpfchen, eine Ausscheidung durch die Nierenepithelien statthaben. ${ }^{2}$ Aber selbst wenn man diesen Einwurf nicht anerkennen will, so ist eine Erklärung schwer zu finden, die den Modus einer Ausscheidung durch die Glomeruli uns als physiologiseh verständlich machte. Von vornherein ist ein Vergleich des Austrittes der Bakterien aus Gefässen mit der Diapedese der weissen oder selbst rothen Blutkörperchen nicht so ohne Weiteres zulässig. In meinem Versuch 6 waren z. B. reichlich rothe Blutkörperchen im Harn, während Bakterien nicht nachgewiesen werden konnten. Kommt es zu einer Diapedese rother Blutkörperchen - ein Vorgang, der zum Mindesten für die

${ }^{1}$ v. Klecki fand einmal ein Bacterium zwischen den Epithelien der gewundenen Canälchen, sonst in Gefässen oder Glomeralis oder im Lumen der Harncanälchen. Ich habe ausser den massenhaften Bakterien in Versuch 3 nur einmal zwei Vibrionen in der Kittsubstanz zwischen den Drüsenepithelien gesehen, sonst fehlten Bakterien im Gewebe gänzlich. Dies wäre wohl nicht möglich, wenn die Ausscheidung durch die Epithelien stattgefunden hätte. S. 539 .

${ }^{2}$ Hofmann, Röhrig, Maas, Wiener, citirt nach Landois, Physiologie. 
Nieren ${ }^{I}$ als pathologisch anzusehen ist - so ziehen sich die ausserordentlich elastischen Blutkörperchen zu dünnen Fäden während des Durchtrittes áus. Dies ist bei den Bakterien, die eine relativ sehr bedentende Starrheit besitzen und häufig noch dazu durch eine Hülle erheblich umfänglicher sind, nicht möglich. Damit wächst auch die Schwierigkeit, einen solchen Austritt als physiologisch ansehen zu können. Nur durch gewaltsame Auseinanderdrängung oder Lähmung der Gefässendothelien wird ein Baktèrium aus dem Gefässlumen herausschlüpfen können. Dies würde eine Verletzung der Gefässwand bedeuten, die wieder einer Reparatur bedarf, also nicht als physiologisch betrachtet werden kann.

Von diesem Gesichtspunkte aus lässt sich auch die Ausscheidung der so sehr viel kleineren Körnchen von Anilinblan durch die Nieren verstehen (Biedl und Kraus).

Mit dem Austritt aus den Gefässen sind die Bakterien aber noch nicht im Harn, sondern erst unter den Epithelien, welche die Gefässschlingen der Glomeruli in ununterbrochener Schicht überziehen. Vm das Ueberwinden auch dieses Hindernisses zu erklären, müsste wieder eine Art Diapedese angenommen werden. In einzelnen Präparaten, die Hr. Dr. Kühnau so gütig war, mir zur Verfügung zu stellen, fanden sich nach Pyocyaneusinjection Massen von Bakterien unter der Glomeruliskapsel, ohne in den freien Raum auszutreten.

Die Behauptung von Biedl und Kraus, dass die Balterien-Ausscheidung durch vermehrte Diurese gleichfalls gesteigert würde, ist durch ihre Versuche nicht bewiesen. Die Unterschiede im zeitlichen Erscheinen der injicirten Mikrobien mit und ohne Anregung der Diurese sind viel zu gering, um diesen Schluss rechtfertigen zu können, ebenso wenig sind die Zahlen der Bakterien, wie sie angeführt werden, beweisend. In v. Klecki's Versuchen war ein solcher Einfluss überhaupt nicht zu erkennen. Auch hierin ist also nichts für eine physiologische Ausscheidung bewiesen.

Von der Besprechung des Ausseheidungsmechanismus wollen Biedl und Kraus die Frage getrennt wissen, inwieweit die Ausscheidung von Mikroorganismen als Schutz- und Heilvorrichtung in Betracht kommt. Dies ist ja auch natürlich, denn die aus dem Kreislauf in der That entfernten Mikroorganismen sind zu wenig zahlreich, um für eine derartige Heilwirkung in Betracht zu kommen. Es ist mir aber nicht verständlich, weshalb man sich dann noch Mühe geben soll, etwas Physiologisehes in dem Mechanismus der Ausscheidung zu suchen, wenn schon von vorn-

${ }^{1}$ Biedl u. Kraus betrachten selbst in ihrer Arbeit (Archiv für experimentelle Pathologie, Bd. XXXVII) den Austritt rother Blutkörperchen in den Harn als Kriterium eines pathologischen Vorganges. 
Durchgängigkeit von Dakm und Nilren für Bakterien. 545

herein feststeht, dass eine derartige Function als Schutz- und Heilvorrichtung des Organismus nicht oder nur in sehr geringem Maasse in Betracht kommen kann. Bei allen sonstigen physiologischen Leistungen unseres Körpers sind wir doch in der lage, eine ausgesprochene Zweckmässigkeit zu erkennen oder zu erschliessen.

Der Nachweis irgend welcher Abhängigkeit der Bakterienausscheidung von der Zahl der im Blute kreisenden Bakterien ist durch v. Klecki trotz seiner gegentheiligen Behauptung nicht erbracht worden. Genau in derselben Weise, wie die Bakterienausscheidung nach erneuter Injection von Bakterien in den Versuchen 11, 14, 23 und 26 begann, setzte sie auch in den Versuchen 24 und 25, nachdem eine Pause eingetreten war, ohne neue Zufuhr wieder ein. In Versuch 14 dauerte es 21 Minuten, bis nach der zweiten Injection Bakterien im Harn wieder erschienen. Bemerkenswerth sind die Culturversuche, die v. Klecki mit den Nieren anstellte. Diese erwiesen sich oft steril, während noch zahlreiche Bakterien im Blute kreisten, entsprechend der Beobachtung, dass in meinen mikroskopischen Präparaten, trotz Injection kolossaler Massen von Bakterien, nur sehr selten ein Keim zu sehen war. Käme es zu einer wirklichen physiologischen Ausscheidung von Bakterien, so müssten, auch wenn sie schubweise erfolgt, doch die Bakterien in den Nieren eher zurückgehalten werden, damit ihre Beförderung nach aussen erfolgen könnte. Auch hierin muss ich einen Beweis gegen eine physiologische Ausscheidung sehen.

Die Forderungen, die wir an eine physiologische Thätigkeit der Nieren stellen müssen, sind also nicht erfüllt. Das Einzige, was dafür spricht, ist die kurze Zeit, nach der injicirte Bakterien im Harne erscheinen können. Indessen ist diese, wie alle anderen beobachteten Erseheinungen, einer zwanglosen Erklärung, zugänglich.

Wir müssen hier zunächst zwisehen pathogenen und toxisch wirkenden Bakterien einerseits und harmlosen andererseits unterscheiden, deren Grenzen allerdings fliessend sind, da wir auch von harmlosen Bakterien wissen, dass sie, in sehr grossen Mengen eingeführt, die Thiere tödten können. Werden Mengen von den ersteren Bakterien in den Kreislauf gebracht, so werden zugleich eine gewisse Menge Toxine, die noch durch den sofort beginnenden Zerfall der Bakterien vermehrt werden, dem Blute beigemischt. Diese werden, je nach der Menge, eine Lähmung oder Abtödtung der weniger widerstandsfähigen Zellen der Gefässe und auch der Nierenepithelien herbeiführen können, zumal nicht, wie bei anderen Vergiftungen, eine allmähliche Gewöhnung stattfinden kann, sondern die Zellen plötzlich der Giftwirkung ausgesetzt werden.

Theils unter dem Drucke des Blutes, theils vermittelst der Eigenbewegungen kann daher eine Zahl von Bakterien die Gefässe schnell ver- 
lassen und nach kurzer Zeit im Harne erscheinen, wobei noch die directe Vergiftung der Zellen durch einzelne angelagerte Balterien (s. oben) unterstützend wirkt. Diese Ausscheidung kann verschieden lange andauern, je nachdem die Sehutzmassregeln des Organismus im Stande sind, die Toxine und die Bakterien selbst unschädlich zu machen oder aus dem Kreislauf zu entfernen und die geschädigten Zellen sich erholen oder durch andere ersetzt werden. Dass diese erste Ausscheidung nur geringe Dimensionen haben kann, hat nichts Befremdliches, da nur ein kleiner Theil der Zellen im Kampfe mit den Giften unterliegen wird. Wir sehen ja auch unter anderen pathologischen Verhältnissen, dass von Zellen, die der gleichen Schädlichkeit ausgesetzt sind, nur ein Theil Veränderungen zeigt und dass z. B. Nekrosen immer herdförmig einsetzen, obwohl sämmtliche Zellen mit den die Nekrose bewirkenden Giften in Berührung kommen. Ein derartig wechselndes Verhalten der Gewebe liefert die Erklärung für die geringe Menge der ausgeschiedenen Bakterien und das atypische Verhalten der Ausscheidung. Dass thatsächlich solche Giftwirkungen und anderweitige Schädigung der Nieren für die Ausscheidung in Betracht kommen, wird durch die Versuche von Cavazzani (12) wahrscheinlich gemacht, der eine Ausscheidung von injicirtem Prodigiosus nur bei gleichzeitiger Pyrogallol- oder Cantharidinverabreichung oder zeitweiser Unterbindung der Arteria renalis erhielt. Hierher gehört auch eine Beobachtung von Sittmann (70), diss die Schnelligkeit der Ausscheidung von Staphylokokken sich mit der Virulenz steigert. - Allmählich werden die im Blute kreisenden Mikrobien aus demselben entfernt, womit natürlich die Ausscheidung auch aufhört. Kommt es später zu einer Weiterentwickelung von Bakterien in den Ablagerungsstätten und zu einer erneuten Aussaat von Mikrobien in den Kreislauf von diesen Herden aus, d. h. also zu einer septico-pyämischen Erkrankung, so kann die Ausscheidung von Bakterien im Harn von Neuem beginnen. Wir haben dann das Bild der Bakteriurie, wie sie für zahlreiche septische Erkrankungen mit Sicherheit nachgewiesen ist, bei der auch Eiweiss und Blut im Harn meist nicht zu fehlen ptlegen und die Nieren degenerative Processe zeigen.

Ist die Menge der injicirten Bakterien zu gross gewesen, als dass sie aus dem Kreislauf entfernt werden könnten, so kann die Ausscheidung fortgehen, wie auch in einem Theile der Versuche von Biedl und Kraus geschehen (2, Seite 20, 8, Seite 11).

Für die ungiftigen Bakterien liegen die Verhältnisse anders. Hier kann natürlich von einer Giftwirkung auf die Gefässzellen ind Nierenepithelien nicht oder nur in sehr beschränktem Maasse die Rede sein. Werden sehr grosse Massen von Bakterien injicirt, so kommt es, wie ohne Weiteres rerständlich, zu Verletzungen der Gefässe, die zu vollständiger 
DurchgängigketT voN DARM UND NIEREN FÜr Bakterien. 547

oder theilweiser Anurie führen können. Wie aus den mikroskopischen Bildern bei meinen Versuchen ersichtlich, treten hier kolossale Hyperämie und Gefässrupturen auf. Die letzteren erfolgen meist nicht in den Glomerulis, trotzdem auch diese ganz riesig ausgedehnt und mit Blutkörperthen strotzend gefüllt sind, sondern meist in dem Capillarnetz, das die Harncanälchen, besonders die gewundenen, umspinnt. Trotzdem erscheinen die Bakterien gewöhnlich erst spät im Harn (das zeitigste ist 51 Minuten nach Beginn der Infusion, ausser in Versuch 3, wo bei Verwendung der alten Cultur eine Giftwirkung vielleicht nicht ausgeschlossen ist), und zwar gleichzeitig mit rothen Blutkörperchen. Ich muss also annehmen, dass Gefässrupturen die Ursache des Uebertrittes von Bakterien in den Urin sind. Solche Rupturstellen werden dureh Blutgerinnsel schnell verstopft und damit hört auch der Bakteriengehalt des Urins wieder auf (Versuch 4, wo nur zwischen 16 und $40 \mathrm{Min}$. im Harn der rechten Niere die injicirten Bakterien sich fanden). Begünstigt werden diese Gefässalterationen noch durch Verwendung nicht filtrirter Bakterienaufschwemmungen, da ja grössere Bröckel gewiss leichter zu Gefässverletzungen führen können. Dies findet eine Erklärung in der Analogie mit dem Entstehen der Endocarditis. ${ }^{1}$

Reichen die Bakterienmengen nicht hin, um Gefässverletzungen und Blutungen herbeizuführen, so bleiben auch die Bakterien im Harne aus, selbst wenn sehr erhebliche Mengen injicirt werden (Versuch 6 und 7) und die Urinsecretion reichlich ist.

Auf eine gewaltige Störung des Gefässsystems, wenigstens der Niere, deutet auch die Verminderung der Urinsecretion bei Infusion sehr grosser Bakterienmassen, trotz Infusion zum Theil grosser Mengen Flüssigkeit in's Gefässsystem, hin. Diese Wirkungen ínjicirter Bakterien mebr mechawischer Art können sich natürlich mit den toxischen Wirkungen bei pathogenen Bakterien vereinigen, und darnach lassen sich die Versuchsresultate von Biedl und hraus und von v. Klecki ganz zwanglos erklären (Versuch 4). Dass auch hier zuweilen Blutungen stattgefunden haben, ist direct aus den Protocollen ron Biedl und Kraus ersichtlich. Wenn man auch keine rothen Blutkörperchen mehr im Harnsedimente beobachten kann, so beweist dies nichts dagegen, dass trotzdem ein Blutaustritt vorher stattgefunden hat. Geringe Mengen desselben können auch der Untersuchung sehr viel leichter entgehen als Bakterien, ausserdem schliesst das Fehlen von Blutkörperchen in dem zu einer Zeit secernirten Harne die Anwesenheit von solchen in anderen Portionen Urins nicht aus, da ja der Austritt von Blutelementen anch wieder aufhören kann. Ueberdies ist Bu. CIII.

1 Wyssokowitsch, Beiträge zur Lehre von der Endbearditis. Vireh. Archiv. 
aus den Protocollen von Biedl und Kraus nicht ersichtlich, ob der Harn, der Bakterien enthielt, jedes Mal gleichzeitig und mikroskopisch auf das Vorhandensein von Blutbestandtheilen and Eiweiss untersucht wurde, und bei dem Fehlen histologiseher Untersuəhungen der Nieren ist das Vorhandensein selbst von Gefässrupturen durchaus nicht ausgeschlossen. Das plötzliche Auftreten und Verschwinden grōsserer Massen von Bakterien im Harn deutet jedenfalls auf eine solche Ursache auch in einem Theil der Fälle hin, in denen kein Blut im Urin beobachtet wurde, nachdem ich durch meine Präparate den Beweis des Vorkommens derselben unter ähnlichen Versuchsbedingungen erbracht habe. Denn wenn schon ungiftige Bakterien im Stande sind, allein durch mechanische Wirkungen Gefässzerreissungen herbeizuführen, wie viel mehr pathogene, bei denen noch die Giftwirkung hinzukommt.

Durch die voranstehenden Erörterungẹn scheint es mir erwiesen, dass von einer physiologischen Ausscheidung von Bakterien durch die Nieren in keiner Richtung die Rede sein kann, selbst nicht in dem Sinne, den Biedl und Kraus dem Worte ,physiologisch" beilegen. Der menschliche oder thierische Körper bedarf ja auch der Nieren gar nicht, um sich von in die Blutbahn eingedrungenen Keimen zu befreien. Wie wir aus den Protocollen der Versuche v. Klecki's and von mir ersehen, nimmt die Keimzahl im Blute, auch ohne dass es zu einer Ausscheidung durch die Nieren kommt, sehr schnell ab. Es steht dies ganz im Einklange mit den von Wyssokowitsch erhaltenen Resultaten, der uns zugleich als Ablagerungs- und Vernichtungsstätten der Mikroorganismen Leber, Milz und Knochenmark kennen lehrte. Wie ausgezeichnet diese Vorrichtung unseres Körpers functionirt, lässt sich durch eine kleine Berechnung deutlich machen. In meinem Versuch 5 erhielt der Hund 10000000 Keime. Von einer 20 Minuten später entnommenen Blutprobe enthielt 1 ecm nur 8 Keime, während die Injectionsmenge 9000 Keime auf $1 \mathrm{~cm}$ Blut betrug. Eine Ergänzung einer solchen Schutzwirkung durch die Nieren brauchen wir also auch nicht einmal zu wünschen.

Aus den Erörterungen ergiebt sich, dass wir bei Infectionskrankheiten von einer vermehrten Diurese eine Heilwirkung in dem Sinne nicht erhoffen dürfen, dass sie im Stande wäre, die Keimzahl im Blute durch directe Ausscheidung zu vermindern. Die Aufgabe der Diurese und auch der Diaphorese dürfte lediglieh in der Entfernung der Stoffiwechselproducte der Bakterien und der Zerfallsproducte der schon im Blute oder in den Ablagerungsstätten vernichteten Keime bestehen. Wir haben also allen Grund, in Krankheitsfällen die Diurese und Diaphorese,zu unterstützen, anch wenn es nicht zu einer Ausscheidung von Bakterien im Harn und Schweiss kommt. - 
Dubchgängigkeit von Darm dND Nieren für Bakterien. 549

Die Resultate der vorliegenden Arbeit fasse ich kurz in Folgendem zusammen:

Die normale Darmwand ist für die Darmbakterien undurchdringlich, ein Uebertritt von Bakterien in den Chylus während der Verdauung findet nicht statt.

Geringe Alterationen der Darmwand vermögen diese Schutzwirkung nicht aufaheben, selbst schwere mechanische und chemische Läsionen führen nur ausnahmsweise zu einem Durchbruch von Bakterien in den Kreislauf.

Ein agonales Eindringen von Keimen in den Kreislauf ist, zum Mindesten vom Darme aus, nicht bewiesen.

Eine physiologische Ausscheidung von im Blute kreisenden Bakterien durch die Nieren giebt es nicht.

Das häufig beobachtete Auftreten von Keimen im Harn schon kurz nach Injectionen in die Blutbahn beruht auf mechanischen und chemischen Verletzungen der Gefässwände und Nierenepithelien.

Anmerkung. Die vorstehende Arbeit wurde am 1. März 1898 abgeschlosseu, die später erschienene Litteratur konnte deshalb nicht berücksichtigt werden. 


\section{Litteratur,}

betreffend Bakterien-Ausscheidung durch die Nieren.

1. Anton und Fütterer. Ref. Baumgarten. 1888. S. 148 .

2. Baumgarten, Patholog. Mykologie. Bd. Il. (Cit. nach B. u. K.)

3. Biedl u. Kraus, Ueber die Ausscheidung der Mikroorganismen dureh die Niere. Archiv für experimentelle Pathologie. Bd. XXXVII. S. 1.

4. Dieselben, Weitere Beiträge über die Ausscheidung der Mikroorganismen durch drüsige Organe. Centralblatt für innere Medicin. 1896. S. 737.

5. Dieselben, Ueber die Ausscheidung der Mikroorganismen durch drïsige ('rgane. Diese Zeitschrift. Bd. XXVI. S. 353.

6. Bouchard, Rev. de méd. expér. 1881. 'T. I. p.671. (v. K.)

7. Boceardi, Sulle permeabilita del glomerulo malpighiano al bac. anthrae. Rif. med. 1888. Ref. Baumgarten. 1888. S. 104.

8. Brunner, Ueber die Ausscheidung pathogener Mikroorganismen durch den Schweiss. Berliner klin. Wochenschrift. 1891. Nr. 21.

9. Derselbe, Deutsche Medicinal-Zeitung. 1896. Nr.1-3 u. 7.

10. Buchner, Beiträge zur Kenntniss des Neapeler Cholerabacillus u. s. w. Archiv für Hygiene. Bd. III. S. 391

11. Canon, Deutsche Zeitschrift für Chirurgie. Bd.XXXVJI. S. 571

12. Cavazzani, Ueber die Absonderung der Bakterien dureh die Nieren. Centralblatt für Fathologie. 1893. Bd. IV. (v. K.)

13. Chamberland et Roux, Annales belges. 1884. Ref. Virchow-Hirsch. 1884. Bd.I. S. 576. (v. K.)

14. Charrin, Note relative à la bactériologie du lait etc. Compt. rend. Soe. biol. 1895. p. 68 . Ref. Baumgarten. S. 606

15. Chvostek, Ueber die Verwerthbarkeit bakteriol. Blnt-Harnbefunde u. s. w. Wiener klin. Wochenschrift. 1895. Nr. 26.

16. Cohn u. Neumann, Ueber den Keimgehalt der Frauenmilch. Virchow's Archiv. Bd. CXXXVI. (v. K.)

17. Cohnheim, Vorlesungen über allgemeine Pathologie. 1882. - Virchow's Archiv. Bd. XL. (B. u. K.)

18. Cotton, Sitzungsberichte der $K . K$. Akademie der Wissenschaften in Wien. 1896. Bd. CV. Abth. III. (Cit. nach Biedl u. Kraus.)

19. v. Eiselsberg, Nachweis von Eiterkokken im Sehweisse einer Pyämischen. Berliner klin. Wochenschrift. 1891. Nr. 23. Ref. Baungarten. 1891. S. 41.

20. Emmerich, Untersuchungen über die Pilze der Cholera asiatica. Archivf: Hygiene. Bd. III. - Fortschritte der Medicin. Bd. XXXV. S. 653.

21. Engel, Experinentelle Untersuchungen über Bacteriurie bei Nephritiden. Deutsches Archiv für klin. Medicin. Bd. LVI. 1 u. 2. Ref. Centralblatt für Bakteriologie. Bd. XIX. S. 76.

22. Enriquez, Recherches bacteriol. sur l'urine normale. Sem. méd. T. IX.

23. Escherich, Bakteriolog. Untersuchungen der Frauenmilch. Ref. Baumgarten. 1885.

24. Faulhaber, Ueber das Vorkommen von Bakterien in den Nieren bei acuten 
Infectionskrankheiten. Zieggler's Beiträge. 1891. Bd. X. Lef. Centralblatt. Bd. X. Ref. Baumgarten. 1891. S. 253 u. 529.

25. v. Fodor, Bakterien im Blute lebender Thiere. Arehiv fir Hygiene. Bd. IV. 26. Derselbe, Neue Versuche mit Injection von Bakterien in die Venen. Deutsche med. Wochenschrift. 1886. S. 617. Ref. Baumgarten. 1886. S. 381.

27. Derselbe, Die Fähigkeit des Blutes, Bakterien zu vernichten. Ebenda. 1887. Nr. 34

28. Franz, Ueber die Bakterien der männlichen Urethra und deren Einfluss auf den Keingehalt des Harns. Wiener klin. Woolhenschrift. 1696. Nr.28. (Chv.)

29. Fütterer, Münchener med. Wochenschr. 1888. Ref. Baumg. 1888. S. 148 .

30. Gärtner, Versuche der praktischen Verwerthung des Nachweises von Eiterkokken im Schweisse Septischer. Centralblatt für Gynäkologie. 1891. Nr. 40. Ref. Baumgarten. 1891. S. 41.

31. Geisler, Ueber Ausscheidung von Typhusbacillen durch den Schweiss. Wratsch. 1893. - Centralblatt für Bakteriologie. Bd. XIII. S. 767.

32. Hinze in Lubarsch-Ostertag, Ergebnisse der allgemeinen Aetiolagie. Wiesbaden 1896. I. (v, K.)

33. Hoffmann u. Langerhans, Ueber den Verbleib des in die Circulation eingeführten Zinnobers. Virchow's Archiv. Bd. XIVIII. (v. K.)

34. Karlifiski, Untersuchungen über das Vorkommen von Typhusbacillen in Urin. Prager med. Wochenschrift. 1890. Ref. Baumgarten. 1890. S. 270.

35. v. Klecki, Archiv für experimentelle Pathologie. Bd. XXXIX.

35a. Konjajeff. Ref. Centralblatt für Bakteriologie. Bd. IV. S. 672.

36. Krans, Bakteriolog. Blut- und Harnuntersuchung. Zeitschr. f. Heilkunde. Bd. XVII. Ref. Centralblatt. Bd. XXI. S. 545.

37. Derselbe, Ueber die Verwerthbarkeit bakteriol. Blut- a. Harnbefunde ete. Wiener klin. Wochenschrift. 1895. Nr. 20. Ref. Centralblatt für Bakteriologie. Bd. XVII. S. 238 .

38. Krase in Flügge, Die Mikroorganismen. I. S. 375 .

39. Kühna u, Ueber die Resultate und die Leistungsfähigkeit d. bakteriol. Blutuntersuchung. Diese Zeitschrift. Bd. XXV. S. 492.

40. Letienne, Rech. bactériol. sur la bille humaine. Arch. de méd. expér. 1891.

41. Longard, Ueber die Identität der Staphylokokken, welche in der Milch u. den Abscessen vorkommen. Ref. Baumgarten. 1886. S. 19.

42. Mass, Deutsche Zeitschrift für Chirurgie. Bd. XII. (B. u. K.)

43. Meyer, Ueber Ausscheidungstuberculose der Nieren. Virchow's Archiv. Bd. CXLI. Ref. Baumgarten. 1895. S. 724.

44. Neumann, Ueber Typhus-Bacillen in Urin. Berliner klin. Wochenschrift. 1890. Nr. 6. Ref. Baumgarten. 1890. S. 229.

45. Derselbe, Ueber ein masernähnliches Exanthem b. Typhus. Ref. Baumgarten. 1890. S. 43 .

46. Derselbe, Ueber die diagnostische Bedeutung der bakteriol. Urinunters. Berliner kiin. Wochenschrift. 1888. Nr. 7.

47. Nissen, Die bakterienvernichtenden Eigenschaften des Blutes. Diese Zeitschrift. Bd. VI. S. 487 .

48. Nuttal, Experimente über die bakterienfeindl. Einflüsse d. thier. Körpers. Ebenda. Bd. IV. S. 88.

49. Orth, Ueber bakterische Ausscheidungserkrankungen d. Nieren. Ref. Baumgarten. 1894. S. 597. 


\section{E. Opitz: DUlohgängigkett v. Darm v. Nieken für Bakterien.}

50. Pernice und Alepi, Le alterazione di sangue etc. Ref. Baumgarten. 1891. S. 531.

51. Pernice und Polacei, Intorno alla influenza della secrezione urniuria ete. Riform. med. 1991. (v. K.)

52. Pernice und Scagliosi, Ueber d. Ausscheidung d. Bakterien aus d. Organismus. Deutsche med. Wochenschrift. 1892. Nr. 34. Ref. Baumgarten. 1892. S. 569.

53. Dieselben, Experimentelle Nephritis bakter. Ursprunges. Ref. Centralblatt für Bakteriologie. Bd. XV und Banmgarten. 1894. S. 563.

54. Philip powicz, Ueber d. Auftreten pathog. Mikroorgan. im Hirne. Ref. Baungarten. 1885 .

55. Ponfick, Archiv für pathol. Anatomie. Bd. XLVIII. (B. u. K.)

56. Posner und Lewin, Ueber krpptogenetische Entzündungen, namentl. dor Harnorgane. Ref. Baumgarten. 1894. S. 594.

57. Preto, Riform. med. 1892. No.21. Ref. Centralbl. f. Bakteriol. Bd.XI. S.445.

58. Queirolo und Penny, La diaforesi nelle malattie infettive febrili. Ref Baumgarten. 1890. S. 559 .

59. Réno n Passage du mycèle de l'Asperg. fumig. dans les urines. Sem. méd. 1896. - Centralblatt für Bakteriologie. 1896.

60. Rib hert, Unsere jetzigen Kenntnisse v. d. Erkrankung der Nieren b. infect. Krankh. Deutsche med. Wochenschrift. 1884. S. 682, u. 1889. S. 39. Baumgarten. 1889. S. 516.

61. Derselbe, Weitere Unters. über d. Schicksal pathog. Pilze im Organismus. Ehenda. 1885. Nr. 42. Baumgarten. 1885. S. 162.

62. Ringel, Ueber d. Keimgehalt d. Frauenmilch. Münchener med. Wochen. sehrift. 1893. Nr. 27. Ref. Centralblatt für Bakteriologie. Bd. XIV. S. 429.

63. Rossbach, Centralblatt für, d. med. Wissenschaften. 1882. \$. 81. (Cliv.)

64. Sauer, Archiv für mikroskopische Anatomie. Bd. XI,VI. S. 109.

65. Scheurlen, Centralblatt für Bakteriologie. Bd. VIII. S. 257.

66. Schweizer, Ueb. d. Durchgehen v. Bacillen durch d. Nieren. Viruhow's Archiv. Bd. CX. Ref. Baumgarten. 1887. S. 410.

67. Sherington, Experiments of the escape of bacteria with the Secretions. Ref. B a umgarten. 1894. S. 611.

68. Siebel, Ueber d. Schicksal von Fremdkörpern in d. Blutbahn. Virchow's Archiv. Bd. CIV.

69. Singer, Bakteriol. Harnuntersuchungen b. acuten Gelenkxheumat. Wiener klin. Wochenschrift. 1894. S. 449. Ref. Centrallbatt für Bakteriologie. Bd. XVIII. S. 130.

70. Sittmaun, Bakterioskop. Blatuntersuchungen etc. Deutsches Archiv fïr klin. Medicin. Bd. LIII. Baumgarten. 1894. S. 26.

71. Solomonson und Dircking Holmfeld, Fortschritte d. Medicin. Bd. II. (Citirt nach Chrostek.)

72. Stricker, Vorlesungen über Pathologie. 1878-1883. (B. u. K.)

73. Sudakow, Ueber die Ausscheidung pathog. Mikroorganismen im Schweiss. Wratseh. 1893. Ref. Centralblatt für Bakteriologie. Bd. XIV. S. 817.

74. Trambusti und Maffucci. Ref. Baumgarten. 1886. S. 382.

75. Wyssokowitsch, Ueber die Schicksale in's Blut injicirter Mikroorganis. men etc. Diese Zeitschrift. Bd. I. S. 1. 